\title{
Article \\ Inhibition of Biofilm Formation by the Synergistic Action of EGCG-S and Antibiotics
}

\author{
Shrameeta Shinde ${ }^{1,2} \mathbb{D}$, Lee H. Lee ${ }^{1, *}$ and Tinchun Chu ${ }^{3, * \mathbb{D}}$ \\ 1 Department of Biology, Montclair State University, Montclair, NJ 07043, USA; shrameeta@gmail.com \\ 2 Department of Microbiology, Miami University, Oxford, OH 45056, USA \\ 3 Department of Biological Sciences, Seton Hall University, South Orange, NJ 07079, USA \\ * Correspondence: Lee.Lee@montclair.edu (L.H.L.); Tinchun.Chu@shu.edu (T.C.)
}

check for updates

Citation: Shinde, S.; Lee, L.H.; Chu, T. Inhibition of Biofilm Formation by the Synergistic Action of EGCG-S and Antibiotics. Antibiotics 2021, 10, 102. https://doi.org/10.3390/ antibiotics 10020102

Academic Editors: David Martin, Merlin Willcox, Xiao-Yang (Mio) Hu and Michael Moore

Received: 31 December 2020

Accepted: 18 January 2021

Published: 21 January 2021

Publisher's Note: MDPI stays neutral with regard to jurisdictional claims in published maps and institutional affiliations.

Copyright: (c) 2021 by the authors. Licensee MDPI, Basel, Switzerland. This article is an open access article distributed under the terms and conditions of the Creative Commons Attribution (CC BY) license (https:/ / creativecommons.org/licenses/by/ $4.0 /)$.

\begin{abstract}
Biofilm, a stress-induced physiological state, is an established means of antimicrobial tolerance. A perpetual increase in multidrug resistant (MDR) infections associated with high mortality and morbidity have been observed in healthcare settings. Multiple studies have indicated that the use of natural products can prevent bacterial growth. Recent studies in the field have identified that epigallocatechin gallate (EGCG), a green tea polyphenol, could disrupt bacterial biofilms. A modified lipid-soluble EGCG, epigallocatechin-3-gallate-stearate (EGCG-S), has enhanced the beneficial properties of green tea. This study focuses on utilizing EGCG-S as a novel synergistic agent with antibiotics to prevent or control biofilm. Different formulations of EGCG-S and selected antibiotics were used to study their combinatorial effects on biofilms produced by five potential pathogenic bacteria, Escherichia coli, Pseudomonas aeruginosa, Staphylococcus aureus, Staphylococcus epidermidis, and Mycobacterium smegmatis. The crystal violet (CV) assay and the sensitive fluorescence-based resazurin biofilm viability assay were used to assess the biofilm production. Our results identified optimal formulation for each bacterium, effectively inhibiting biofilm formation to an extent of 95-99\%. Colony-forming unit (CFU) and cell viability analyses showed a decrease of viable bacteria. These results depict the potential of EGCG-S as a synergistic agent with antibiotics and as an anti-biofilm agent.
\end{abstract}

Keywords: biofilm; green tea polyphenol; antibiotics; EGCG-S

\section{Introduction}

Selective environmental pressures force bacteria to adapt by altering their growth state. One preferred state is biofilm, which exists in almost $90 \%$ of bacteria. Biofilm is a three-dimensional, multicellular surface-tethered bacterial aggregation embedded in an extracellular matrix (ECM). During biofilm formation, planktonic cells attach to surface and transition to the sessile state to secrete an extracellular polymeric substance (EPS) forming a protective barrier against abiotic and biotic stressors. Upon maturation of biofilm, the cells are shed for dispersal which then transition into planktonic cells [1]. Biofilm is an inherent physiological and regulatory strategy for being refractory to antimicrobial treatments and the host immune system [1,2]. Clinically relevant biofilm-associated infections are either tissue or device-related infections. Chronic tissue infections include wounds, dental plaque, urinary tract infection, cystic fibrosis, and so on, while medical devices like catheters, prosthetic heart valves, orthopedic implants, and so on are colonized by bacteria [3].

Up to $65 \%$ and $80 \%$ of microbial and chronic infections respectively are linked to bacterial biofilms [4]. Additionally, recurrent bacterial infections are due to the persistent nature of the biofilms [1]. Currently, ESKAPE group organisms (Enterococcus faecium, Staphylococcus aureus, Klebsiella pneumoniae, Acinetobacter baumannii, Pseudomonas aeruginosa, and Enterobacter spp.) are the most prevalent cause of multidrug resistant biofilm-associated chronic infections [5]. Certain biofilm producers, such as Staphylococcus epidermidis and the ESKAPE group, have been implicated in nosocomial infections from contaminated 
medical devices [6,7]. Biofilm plays a critical role in the pathogenesis of chronic diseases like tuberculosis and cystic fibrosis [8]. Treatment of biofilm-associated infections is becoming increasingly difficult due to multidrug resistance, and thereby they still pose a significant risk to human health. This study focuses on optimizing and evaluating different formulations to find effective therapeutics for biofilm-related bacterial infections.

Green tea, derived from Camellia sinensis, has held a significant place for a long time in traditional medicine. It is the second most popular beverage consumed in the world [9]. Epigallocatechin gallate (EGCG), the most abundant polyphenol/catechin in green tea, has been attributed numerous health benefits including antioxidant, antiinflammatory, anti-cancerous, and antimicrobial properties [10-13]. United States Food and Drug Administration (FDA) classified EGCG as a safe compound due to its non-toxic nature and lack of side effects after application or consumption [14,15]. Many studies indicated antimicrobial $[16,17]$ and anti-biofilm activity of EGCG on various Gram-positive and Gram-negative bacteria [18]. Parallel studies suggested synergism of antibiotics and EGCG on bacterial growth wherein EGCG is shown to enhance bacterial susceptibility, including methicillin-resistant Staphylococcus aureus (MRSA), Porphyromonas gingivalis (P. gingivalis) and Klebsiella pneumoniae (K. pneumoniae) to antibiotics [19-23].

Besides the beneficial properties, the natural water-soluble form of EGCG is relatively unstable, which affects its bioavailability and makes formulations difficult [24-26]. The rapid metabolism of EGCG results in a loss of therapeutic properties [19]. Several modifications of green tea polyphenols (GTPs) were synthesized to resolve the stability issue. Lipid-soluble analogs were found to be effective GTPs as they were highly stable with improved bioavailability [27]. Modified lipophilic polyphenols (LTPs) were shown to act synergistically with antibiotics to inhibit the growth of various Gram-positive and Gram-negative bacteria [19]. Another lipophilic EGCG derivative, EGCG-palmitate-based formulations exhibited sporicidal activity [28,29]. Recently, a derivative of EGCG known as epigallocatechin-3-gallate-stearate (EGCG-S) was synthesized by esterification of fatty acid making EGCG lipophilic and thereby, enhancing its absorption in the lipid bilayer. EGCG-S has been successfully shown to inhibit spores produced by Bacillus spp. and the growth of Streptococcus mutans (S. mutans) [30,31]. Additionally, EGCG-S was shown to improve the efficacy of antibiotics against various bacteria, thereby making it a potential synergistic anti-bacterial agent [32]. Various antibiotics have been previously shown to have synergism with EGCG/EGCG-S to inhibit bacterial growth [32]. The bacteria were more susceptible to specific antibiotics such as tetracycline and erythromycin respectively when used in combination with EGCG/EGCG-S [32].

In this study biofilm formation in five potentially pathogenic bacteria, including Escherichia coli (E. coli), Mycobacterium smegmatis (M. smegmatis), Pseudomonas aeruginosa (P. aeruginosa), Staphylococcus aureus (S. aureus), and Staphylococcus epidermidis (S. epidermidis) were studied. E. coli has been implicated in urinary tract infections (UTIs) [33]. The biofilm associated UTIs are frequently found in patients that use catheters [34,35]. The non-infectious $M$. smegmatis was used as a surrogate for $M$. tuberculosis as they share growth characteristics [36]. Both strains have been used as model organisms for biofilm studies [37]. Development of $M$. tuberculosis biofilm leads to cavity formation and necrosis in lung tissue [38]. P. aeruginosa is a major cause of nosocomial infections that fail to resolve with antibiotic treatment. Biofilms of these bacteria are found on implanted and indwelling devices [39]. S. aureus biofilm is one of the major hallmarks of cystic fibrosis respiratory infections. These infections have become refractory to antibiotics and have led to emergence of methicillin-resistant S. aureus (MRSA) [40]. S. epidermidis, a human commensal microorganism, is a causative agent of chronic infections in compromised hosts [41]. These infections are associated with the introduction of foreign biomaterials like catheters and prostheses [42]. All biofilm infections are becoming highly recalcitrant to host immune system and multiple drugs.

The classic biofilm measurements are based on direct cell enumeration by colony forming unit (CFU) counting and indirect biofilm accumulation by crystal violet (CV) 
staining. However, these techniques require biofilm resuspension and the potential carryover of the antimicrobials may skew the results [43]. Resazurin assay rapidly quantifies metabolic cell activity, is sensitive, simple, and requires no biofilm isolation [44]. This assay is a preferred choice for biofilm quantification [45] and is widely used in biofilmassociated studies [46-48].Therefore, this study utilized three independent quantitative assays, CFU analysis, CV staining, and resazurin, to ensure consistent data with high confidence. Furthermore, a fluorescent dye-based microscopic analysis was performed to study the viability of the cells. According to Clinical Laboratory Standards Institute (CLSI) Kirby-Bauer disk diffusion [49] profiling results, E. coli and M. smegmatis were intermediate to erythromycin while $P$. aeruginosa was resistant to erythromycin. Both S. aureus and S. epidermidis were intermediate to tetracycline. We previously reported that EGCG-S can enhance the erythromycin on Gram-negative bacteria such as E. coli, P. aeruginosa and converted the bacteria from antibiotic resistant or intermediate category to sensitive. EGCG-S can enhance tetracycline on S. aureus and S. epidermidis and converted the bacteria from antibiotic resistant or intermediate category to sensitive [32]. In this study, erythromycin was used on the Gram-negative and acid-fast bacteria; tetracycline was used on Grampositive bacteria to study the synergistic action of EGCG-S and erythromycin/tetracycline in inhibiting biofilm production.

\section{Results}

\subsection{The Effect of Erythromycin and EGCG-S on E. coli Biofilm Formation}

The inhibitory effect of erythromycin (E) and EGCG-S (ES) treatments, individually and/or in combination, on E. coli biofilm formation was evaluated by CFU analysis. Based on the extent of inhibition, individual lethal dose $\left(\mathrm{LD}_{50}\right)$ for erythromycin and EGCG-S were identified to be $15 \mu \mathrm{g} / \mathrm{mL}$ (E15) and $50 \mu \mathrm{g} / \mathrm{mL}$ (ES50) respectively. However, since biofilm is more tolerant to most of the treatment $[1,2]$ it was hypothesized that the abovestated combinations will not be the optimal formulation for inhibiting biofilm production and thus, numerous combinations of erythromycin (E) and EGCG-S (ES) with variable concentrations were tested, along with individual treatments. The effect of individual and combination treatments on biofilm production in E. coli was monitored using colonyforming unit (CFU) assay. CFU measurements were used to calculate log reduction and percentage of inhibition. On testing the first combination comprising of individual $\mathrm{LD}_{50}$ concentrations (E15+ES50), the log reduction of 1.04 with only $94 \%$ inhibition was obtained. This data strongly suggests that combinations with higher concentrations are required to inhibit biofilm formation. In comparison to the control, the log reductions and percentage of inhibition showed by different formulations of $\mathrm{E}$ and $\mathrm{ES}$ are summarized in Table 1.

Table 1. Colony-forming units $(\mathrm{CFU} / \mathrm{mL})$ and respective log reduction and percentage of inhibition for different treatments on biofilm formation in E. coli. E: erythromycin; ES: epigallocatechin-3-gallatestearate (EGCG-S).

\begin{tabular}{cccc}
\hline $\begin{array}{c}\text { Treatments } \\
(\mu \mathbf{g} / \mathbf{m L})\end{array}$ & CFU/mL (Mean $\pm \mathbf{S D})$ & Log Reduction & $\begin{array}{c}\text { Avg } \\
\text { \% Inhibition }\end{array}$ \\
\hline E0+ES0 & $(1.81 \pm 0.02) \times 10^{6}$ & 0 & 0 \\
E10 & $(1.34 \pm 0.09) \times 10^{6}$ & 0.13 & 27.01 \\
E15 & $(1.10 \pm 0.03) \times 10^{6}$ & 0.22 & 40.52 \\
ES50 & $(8.72 \pm 0.90) \times 10^{5}$ & 0.32 & 53.39 \\
E10+ES100 & $(3.00 \pm 0.23) \times 10^{5}$ & 0.78 & 86.07 \\
E10+ES150 & $(9.00 \pm 0.43) \times 10^{4}$ & 1.30 & 98.04 \\
E10+ES200 & $(1.10 \pm 0.15) \times 10^{5}$ & 1.22 & 96.93 \\
E15+ES25 & $(1.85 \pm 0.10) \times 10^{5}$ & 0.99 & 92.65 \\
E15+ES50 & $(1.65 \pm 0.07) \times 10^{5}$ & 1.04 & 93.77 \\
\hline
\end{tabular}

Various formulations were tested for their inhibitory effect, and only two combinations E10+ES150 and E10+ES200 showed the highest log reduction of 1.3 and 1.22, respectively. 
The respective percentage of inhibition was $98 \%$ and $97 \%(p<0.05)$. To further strengthen the CFU data, biofilm quantification was performed using CV and resazurin assay. The results of the CV analysis are represented in Figure 1A. Both E10+ES150 and E10+ES200 showed approximately $97 \%$ inhibition of biofilm using CV assay. However, CV assay is relatively error-prone, and thus fluorescence measurements using resazurin assay demonstrated that for samples treated with E10+ES150 and E10+ES200, the biofilm formation was significantly inhibited by $94 \%$ and $97 \%$ respectively, as depicted in Figure 1B. A highly significant difference compare with the negative control group was found $(p<0.05)$. Fluorescence microscopy was used to evaluate cell viability of treatment with E10, E15, ES50 and with two formulations, namely E10+ES150 and E10+ES200, as shown in Figure 2. The control/untreated group represented a bacterial cell population that fluoresced green (Figure 2A), indicating that most of the population was viable. Single treated with E10, E15, and ES50 did not affect the cell viability significantly. After treatment with $10 \mu \mathrm{g} / \mathrm{mL}$ of erythromycin and $200 \mu \mathrm{g} / \mathrm{mL}$ EGCG-S, almost the entire population fluoresced red indicating that most cells were dead (Figure 2F). Thus, the formulation containing E10+ES200 is significantly effective in inhibiting $E$. coli biofilm production.

A

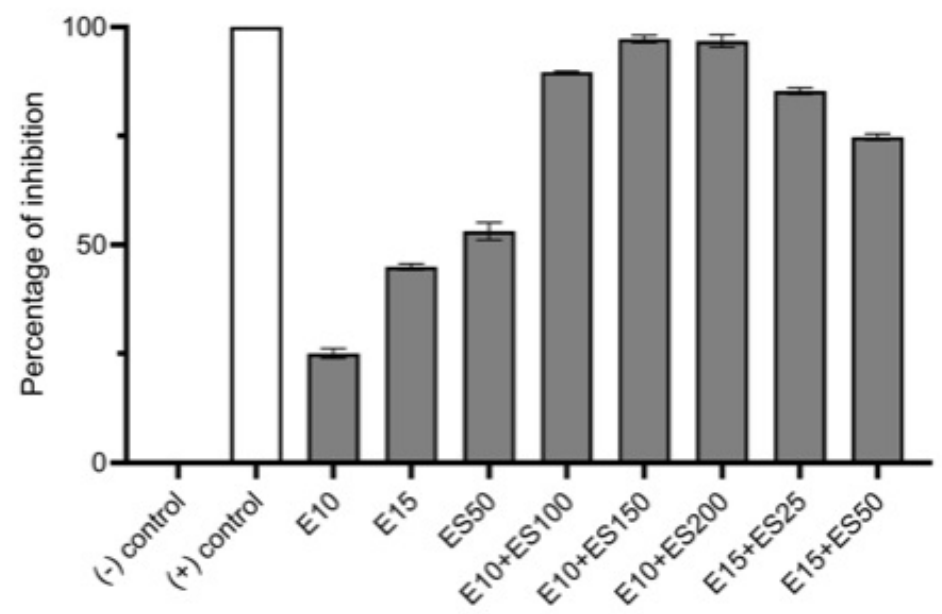

B

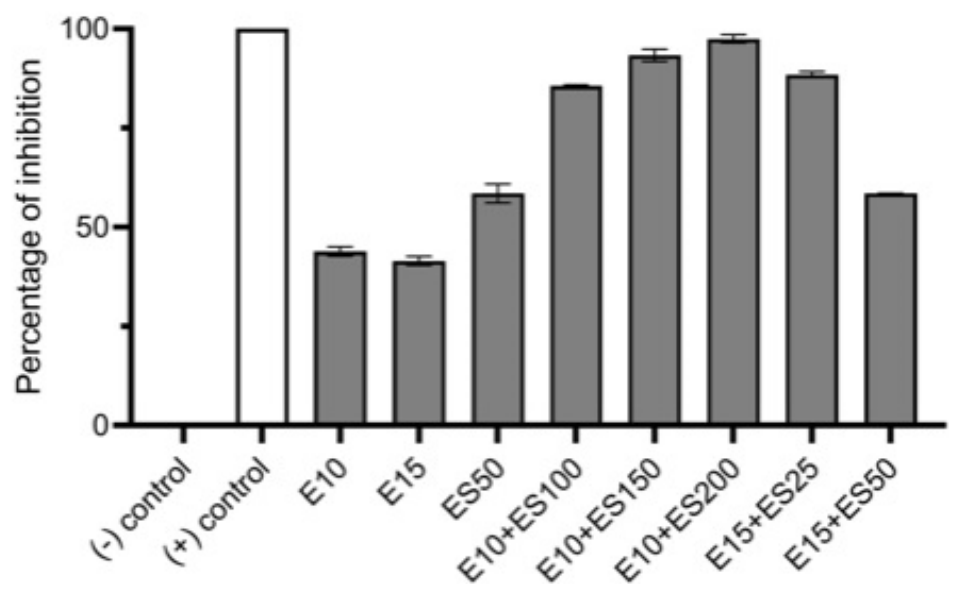

Figure 1. Effect of single and combined treatments of erythromycin (E) and EGCG-S (ES) on biofilm formation in E. coli. The percentage of inhibition for (A) crystal violet assay and (B) Resazurin assay were calculated from respective measurement. (-) control: phosphate buffer saline (PBS) buffer; $(+)$ control: $10 \%$ bleach. Experiments were repeated in triplicates. Means are shown with SD. The percentage of inhibition with different concentrations of erythromycin and EGCG-S indicated that E10+ES200 inhibits E. coli biofilm formation most effectively. 

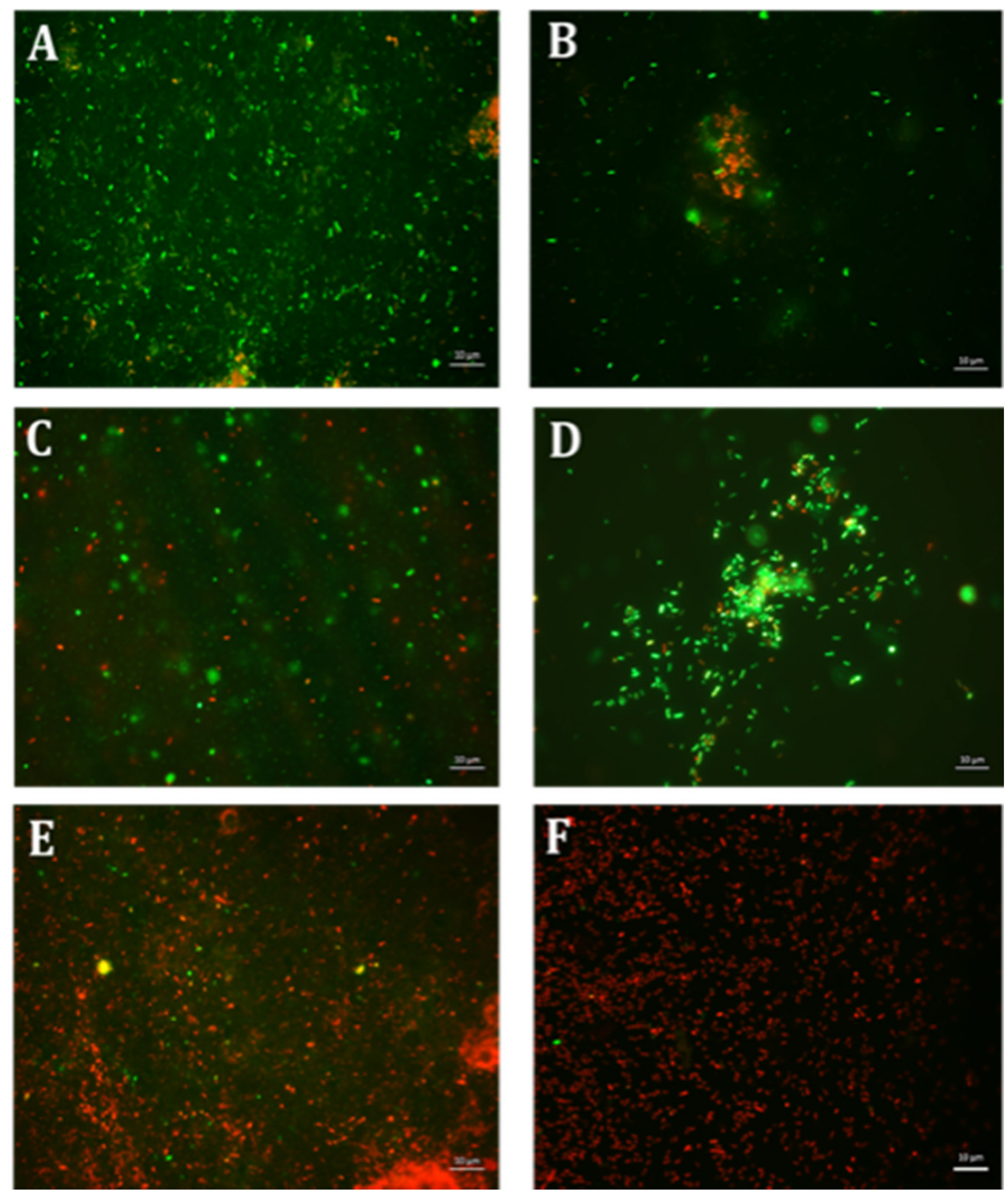

Figure 2. Fluorescence microscopic observation of cell viability on E. coli biofilm formation. E: erythromycin; ES: EGCG-S. Scale bar = $10 \mu \mathrm{m}$. (A) Control, (B) E10, (C) E15, (D) ES50, (E) E10+ES150, and (F) E10+ES200. The results indicated that both E10+ES150 and E10+ES200 severely affect the integrity of the cells and E10+ES200 is the most effective formulation.

\subsection{The Effect of Erythromycin and EGCG-S on M. smegmatis Biofilm Formation}

Preliminary analysis identified $15 \mu \mathrm{g} / \mathrm{mL}$ of erythromycin (E15) and $100 \mu \mathrm{g} / \mathrm{mL}$ of EGCG-S (ES100) as LD 50 for inhibition of bacterial biofilm formation. On comparing the inhibitory action on biofilm formation, based on CFU assay, the combination of E15+ES100 exhibited $72 \%$ inhibition with low log reduction, 0.51 (Table 2). Thus, varying the EGCG-S concentration in the combination, in CFU analysis, identified a formulation, E15+ES150, that significantly increased log reduction to 1.07 and showed $95 \%$ biofilm inhibition. Additionally, biofilm measurements, using CV and resazurin assay, calculated the percentage of inhibition of M. smegmatis biofilm to be $94 \%$ and $99 \%$, respectively. The biofilm inhibition percentage for different treatments is shown in Figure 3. The percentage of inhibition was found to be statistically significant compared with the negative control at $p<0.05$. The sample treated with a combination of E15+ES150 was further qualitatively tested for cell viability and was found to be non-viable, depicted in Figure 4, when compared to the control. Together, it can be concluded that the E15+ES150 formulation optimally inhibits the biofilm formation process in M. smegmatis. 
Table 2. Colony-forming units $(\mathrm{CFU} / \mathrm{mL})$ and respective log reduction and percentage of inhibition for different treatments on biofilm formation in M. smegmatis. E: erythromycin; ES: EGCG-S.

\begin{tabular}{cccc}
\hline $\begin{array}{c}\text { Treatments } \\
(\mu \mathbf{g} / \mathbf{m L})\end{array}$ & CFU/mL (Mean $\pm \mathbf{S D})$ & Log Reduction & $\begin{array}{c}\text { Avg } \\
\text { \% Inhibition }\end{array}$ \\
\hline E0+ES0 & $(1.60 \pm 0.07) \times 10^{5}$ & 0 & 0 \\
E10 & $(1.18 \pm 0.05) \times 10^{5}$ & 0.13 & 27.16 \\
E15 & $(8.30 \pm 0.65) \times 10^{4}$ & 0.29 & 49.91 \\
ES100 & $(7.75 \pm 0.62) \times 10^{4}$ & 0.31 & 53.33 \\
ES150 & $(9.20 \pm 0.25) \times 10^{4}$ & 0.24 & 43.99 \\
E15+ES50 & $(4.40 \pm 0.33) \times 10^{4}$ & 0.56 & 75.20 \\
E15+ES100 & $(4.85 \pm 0.23) \times 10^{4}$ & 0.52 & 72.33 \\
E15+ES150 & $(1.35 \pm 0.03) \times 10^{4}$ & 1.07 & 94.84 \\
E15+ES200 & $(3.75 \pm 0.11) \times 10^{4}$ & 0.63 & 79.38 \\
\hline
\end{tabular}

A

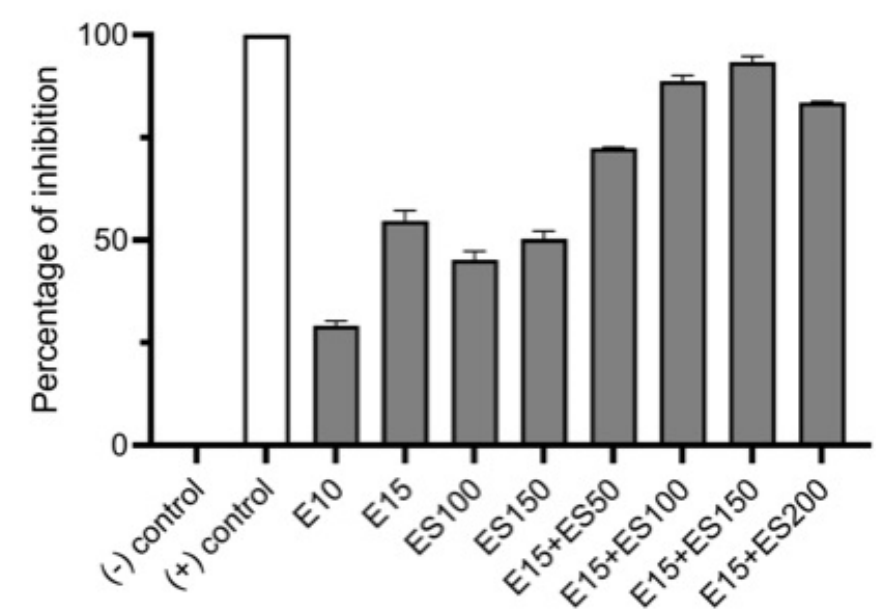

B

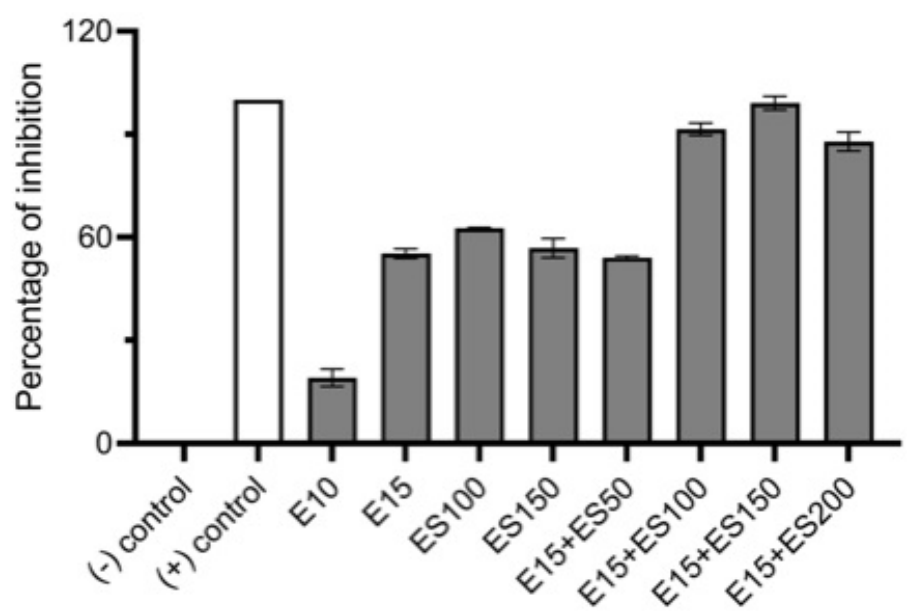

Figure 3. Effect of single and combinatorial treatments of erythromycin (E) and EGCG-S (ES) on biofilm formation in M. smegmatis. The percentage of inhibition for (A) crystal violet assay and (B) Resazurin assay were calculated from respective measurement. (-) control: PBS buffer; (+) control: $10 \%$ bleach. Experiments were repeated in triplicates. Means are shown with SD. The percentage of inhibition with different concentrations of erythromycin and EGCG-S indicated that E10+ES150 inhibits M. smegmatis biofilm formation most effectively. 

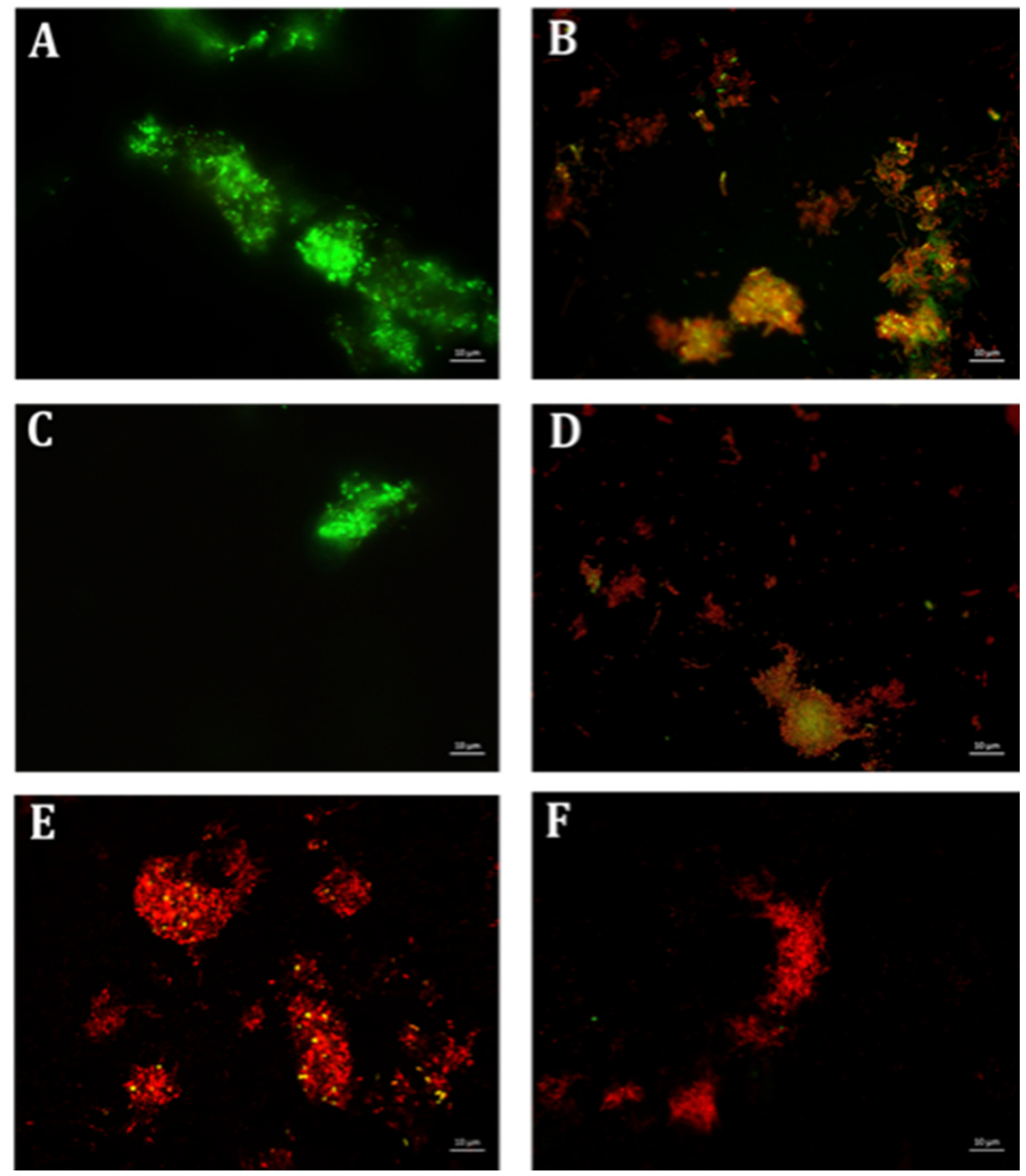

Figure 4. Fluorescence microscopic observation of cell viability on M. smegmatis biofilm formation. E: erythromycin; ES: EGCG-S. Scale bar = $10 \mu \mathrm{m}$. (A) Control, (B) E15, (C) ES100, (D) ES150, (E) E15+ES100, and (F) E15+ES150. The results indicated that E15+ES150 severely affect the viability of the cells.

\subsection{The Effect of Erythromycin and EGCG-S on P. aeruginosa Biofilm Formation}

Biofilm formation of $P$. aeruginosa was evaluated in the presence of multiple concentrations of erythromycin and EGCG-S applied individually to determine E15 and ES50 as LD 50 . In addition, based on CFU assay (Table 3), a treatment combining the $\mathrm{LD}_{50}$ concentrations E15+ES50 demonstrated a mere $83 \%$ inhibition of biofilm production with only $0.61 \mathrm{log}$ reduction of bacterial cells. Numerous combinations with higher concentrations of $E$ and ES were further tested for their efficacy in inhibiting biofilm formation. Increased EGCG-S concentration to $100 \mu \mathrm{g} / \mathrm{mL}$ combined with E15 exhibited the highest log reduction of 0.88 with $95 \%$ inhibition of biofilm. Data obtained from CV and Resazurin assays, shown in Figure 5, identified E15+ES100 as optimal formulation as it inhibited biofilm formation by $97 \%$ and $99 \%$ respectively. The data within the groups was found to be highly significant $(p<0.05)$ compared with the negative control. Supplementary combinations of E15 with a low concentration of EGCG-S, ES50, gave a 91\% inhibition of biofilm formation and hence, the optimal concentration was confirmed using qualitative bacterial viability assay. The microscopic images of control and treated samples are shown in Figure 6. The green 
fluorescence of the control sample indicated live bacterial cells in a biofilm. Mixed live and dead cells were observed in E15, ES25, ES50, E15+ES50 treated samples, while in treatment with the E15+ES100 formulation bacterial cells in the biofilm were no longer viable. Taken together, the biofilm formation process in P. aeruginosa is inhibited optimally by E15+ES100 formulation.

Table 3. Colony-forming units $(\mathrm{CFU} / \mathrm{mL})$ and respective log reduction and percentage of inhibition for different treatments on biofilm formation in P. aeruginosa. E: erythromycin; ES: EGCG-S.

\begin{tabular}{cccc}
\hline $\begin{array}{c}\text { Treatments } \\
(\mu \mathbf{g} / \mathbf{m L})\end{array}$ & CFU/mL (Mean $\pm \mathbf{S D )}$ & Log Reduction & $\begin{array}{c}\text { Avg } \\
\text { \% Inhibition }\end{array}$ \\
\hline E0+ES0 & $(3.40 \pm 0.36) \times 10^{6}$ & 0 & 0 \\
E10 & $(1.41 \pm 0.09) \times 10^{6}$ & 0.38 & 61.14 \\
E15 & $(1.53 \pm 0.12) \times 10^{6}$ & 0.35 & 57.47 \\
ES25 & $(2.00 \pm 0.12) \times 10^{6}$ & 0.23 & 42.99 \\
ES50 & $(1.74 \pm 0.14) \times 10^{6}$ & 0.29 & 51.10 \\
E10+ES200 & $(1.39 \pm 0.05) \times 10^{6}$ & 0.39 & 64.65 \\
E15+ES25 & $(1.48 \pm 0.15) \times 10^{5}$ & 0.36 & 59.12 \\
E15+ES50 & $(8.25 \pm 0.85) \times 10^{5}$ & 0.61 & 83.00 \\
E15+ES100 & $(4.45 \pm 0.36) \times 10^{5}$ & 0.88 & 95.10 \\
E15+ES150 & $(1.44 \pm 0.07) \times 10^{6}$ & 0.37 & 63.02 \\
\hline
\end{tabular}

A

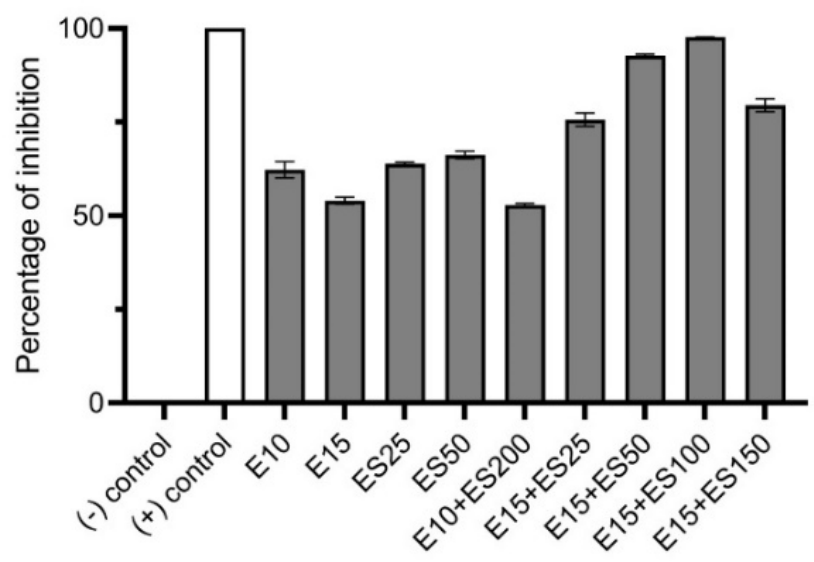

B

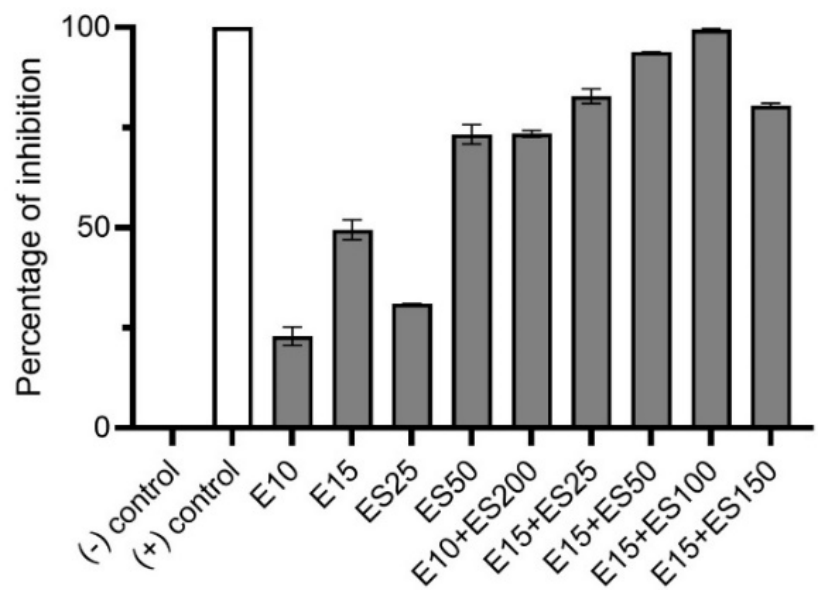

Figure 5. Effect of single and combinatorial treatments of erythromycin (E) and EGCG-S (ES) on biofilm formation in P. aeruginosa. The percentage of inhibition for (A) crystal violet assay and (B) Resazurin assay were calculated from respective measurement. (-) control: PBS buffer; $(+)$ control: $10 \%$ bleach. Experiments were repeated in triplicates. Means are shown with SD. The percentage of inhibition with different concentrations of erythromycin and EGCG-S indicated that E10+ES100 concentration effectively inhibits biofilm formation of $P$. aeruginosa. 

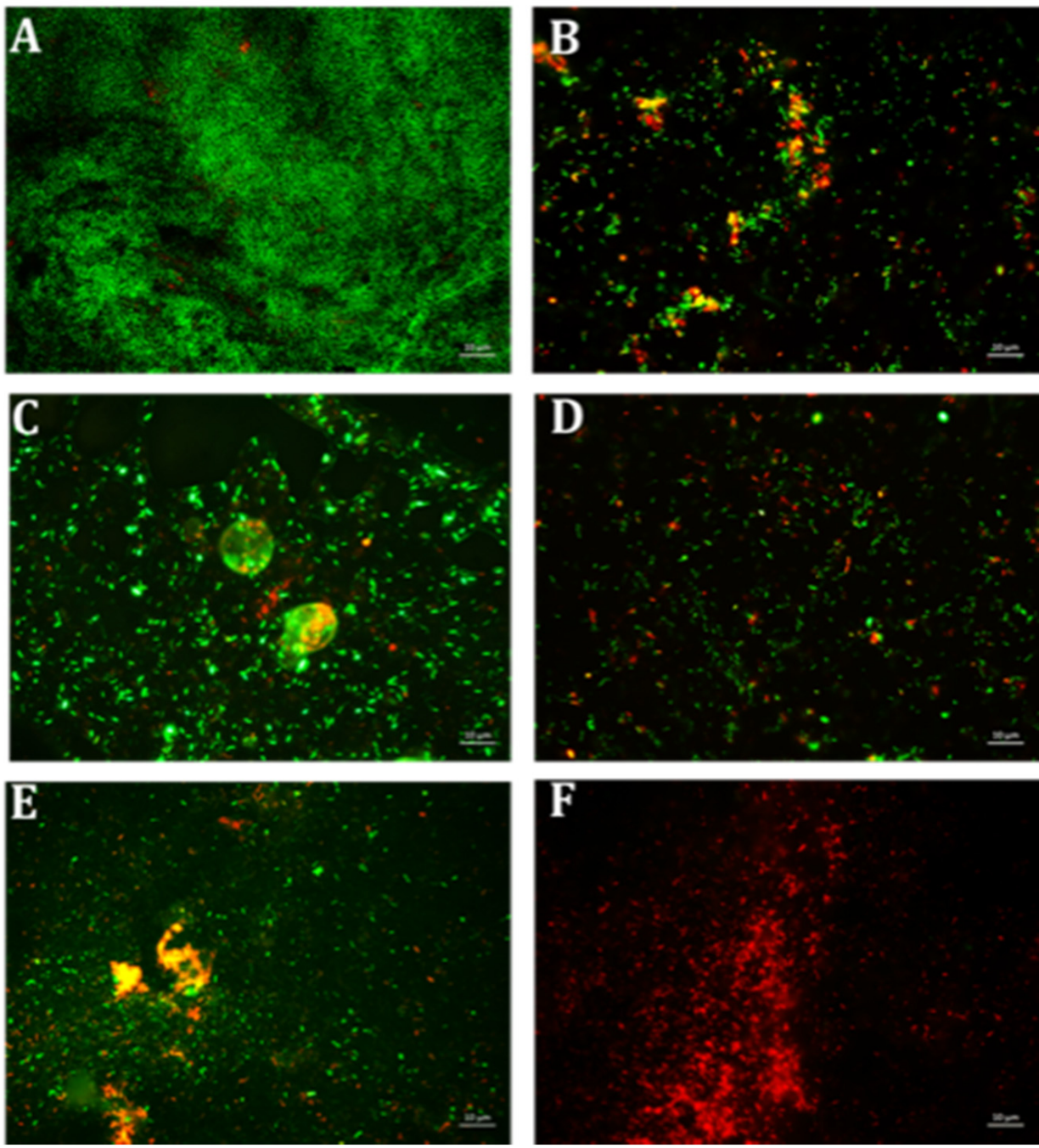

Figure 6. Fluorescence microscopic observation of cell viability on P. aeruginosa biofilm formation. E: erythromycin; ES: EGCG-S. Scale bar $=10 \mu \mathrm{m}$. (A) Control, (B) E15, (C) ES25, (D) ES50, (E) E15+ES50, and (F) E15+ES100. The results indicated that E15+ES100 severely affect the viability of the cells.

\subsection{Synergistic Inhibitory Effect of Tetracycline and EGCG-S on Staphylococcus spp.}

The Staphylococcus genus includes two important potential pathogenic strains: $S$. aureus and S. epidermidis. These Gram-positive organisms are well-known for chronic biofilmassociated infections. Individual and combination treatments were then applied to estimate the extent of inhibition on biofilm formation of Staphylococcus spp. using CFU assay; preliminary CFU analysis on biofilm formed by $S$. aureus identified $15 \mu \mathrm{g} / \mathrm{mL}$ of tetracycline (TE15) and $50 \mu \mathrm{g} / \mathrm{mL}$ EGCG-S (ES50) as LD 50 , respectively. The inhibition exhibited by a combination of TE15+ES50 on $S$. aureus biofilm was only $57 \%$ with a corresponding $\log$ reduction of 0.30 . However, increasing the ES concentration led to conclude that TE15+ES200 formulation was optimal in reducing biofilm formation as it showed a log reduction of 0.75 and $94 \%$ inhibition (Table 4). For S. epidermidis, $\mathrm{LD}_{50}$ for inhibiting bacterial biofilm is $15 \mu \mathrm{g} / \mathrm{mL}$ of tetracycline (TE15) and $100 \mu \mathrm{g} / \mathrm{mL}$ EGCG-S (ES100) respectively. TE15+ES100 formulation comprising the $\mathrm{LD}_{50}$ concentrations that maximally inhibited S. epidermidis biofilm formation by $72 \%$ with a mere log reduction of 0.55 whereas other combinations with a higher concentration of ES increased the inhibitory effect. Finally, the TE15+ES250 formulation showed maximal inhibition of 95\% and increased log reduction to 1.33 (Table 5). 
Table 4. Colony-forming units $(\mathrm{CFU} / \mathrm{mL})$ and respective log reduction and percentage of inhibition for different treatments on biofilm formation in S. aureus. E: erythromycin; ES: EGCG-S.

\begin{tabular}{cccc}
\hline $\begin{array}{c}\text { Treatments } \\
(\boldsymbol{\mu} \mathbf{g} / \mathbf{m L})\end{array}$ & CFU/mL (Mean $\pm \mathbf{S D})$ & Log Reduction & $\begin{array}{c}\text { Avg } \\
\text { \% Inhibition }\end{array}$ \\
\hline TE0+ES0 & $(4.41 \pm 0.34) \times 10^{6}$ & 0 & 0 \\
TE15 & $(2.29 \pm 0.18) \times 10^{6}$ & 0.29 & 52.65 \\
TE30 & $(2.00 \pm 0.16) \times 10^{6}$ & 0.34 & 59.38 \\
ES50 & $(3.18 \pm 0.27) \times 10^{6}$ & 0.14 & 30.14 \\
ES150 & $(1.59 \pm 0.11) \times 10^{6}$ & 0.44 & 69.40 \\
ES200 & $(2.01 \pm 0.15) \times 10^{6}$ & 0.34 & 59.07 \\
TE15+ES50 & $(2.20 \pm 0.34) \times 10^{6}$ & 0.30 & 57.37 \\
TE15+ES100 & $(2.03 \pm 0.20) \times 10^{6}$ & 0.34 & 61.73 \\
TE15+ES150 & $(9.45 \pm 0.37) \times 10^{5}$ & 0.67 & 89.88 \\
TE15+ES200 & $(7.75 \pm 0.62) \times 10^{5}$ & 0.75 & 73.35 \\
TE15+ES250 & $(1.58 \pm 0.04) \times 10^{6}$ & 0.45 & 73.53 \\
\hline
\end{tabular}

Table 5. Colony-forming units $(\mathrm{CFU} / \mathrm{mL})$ and respective log reduction and percentage of inhibition for different treatments on biofilm formation in S. epidermidis. TE: tetracycline; ES: EGCG-S.

\begin{tabular}{cccc}
\hline $\begin{array}{c}\text { Treatments } \\
(\mu \mathbf{g} / \mathbf{m L})\end{array}$ & CFU/mL (Mean $\pm \mathbf{S D})$ & Log Reduction & $\begin{array}{c}\text { Avg } \\
\text { \% Inhibition }\end{array}$ \\
\hline TE0+ES0 & $(4.72 \pm 0.15) \times 10^{6}$ & 0 & 0 \\
TE15 & $(2.10 \pm 0.35) \times 10^{6}$ & 0.35 & 55.52 \\
TE30 & $(2.03 \pm 0.16) \times 10^{6}$ & 0.37 & 56.95 \\
ES50 & $(3.15 \pm 0.29) \times 10^{6}$ & 0.18 & 33.36 \\
ES100 & $(2.35 \pm 0.50) \times 10^{6}$ & 0.30 & 50.20 \\
TE15+ES100 & $(1.34 \pm 0.23) \times 10^{6}$ & 0.55 & 71.69 \\
TE15+ES200 & $(4.78 \pm 0.64) \times 10^{5}$ & 0.99 & 89.87 \\
TE15+ES250 & $(2.19 \pm 0.25) \times 10^{5}$ & 1.33 & 95.36 \\
TE15+ES500 & $(1.71 \pm 0.01) \times 10^{6}$ & 0.44 & 63.72 \\
\hline
\end{tabular}

Using CV and resazurin assays to quantitively study biofilm formation in S. aureus identified that TE15+ES200 as the optimal combination exhibiting $97 \%$ and $98 \%$ inhibition of $S$. aureus biofilm respectively as shown in Figure 7. The TE15+ES200 formulation severely affected the viability of S. aureus cells (Figure 8). Similarly, in the case of S. epidermidis as shown in Figure 9, suggested that a combination of TE15+ES250 is effective in inhibiting biofilm formation to $99 \%$ and $97 \%$, respectively. All quantitative data were subjected to statistical analyses and found that comparing with negative control was significant at $p<0.05$. Furthermore, microscopic viability analysis demonstrated the death of S. epidermidis cells biofilm on treatment with above-stated combinations when compared to live cells in control, as shown in Figure 10. In conclusion, the optimal combination of green tea polyphenol, EGCG-S, and tetracycline that inhibited biofilm formation of S. aureus and S. epidermidis were found to be TE15+ES200 and TE15+ES250, respectively. 
A

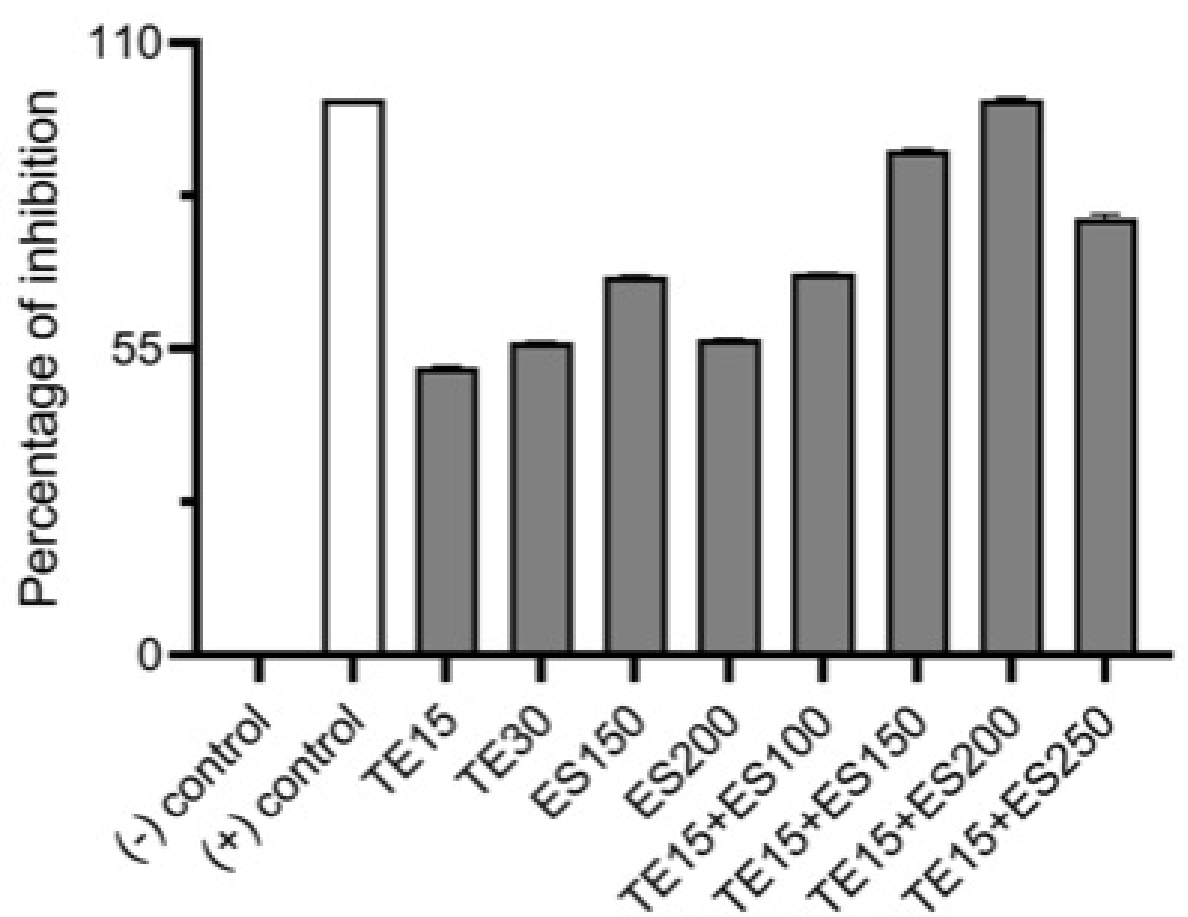

B

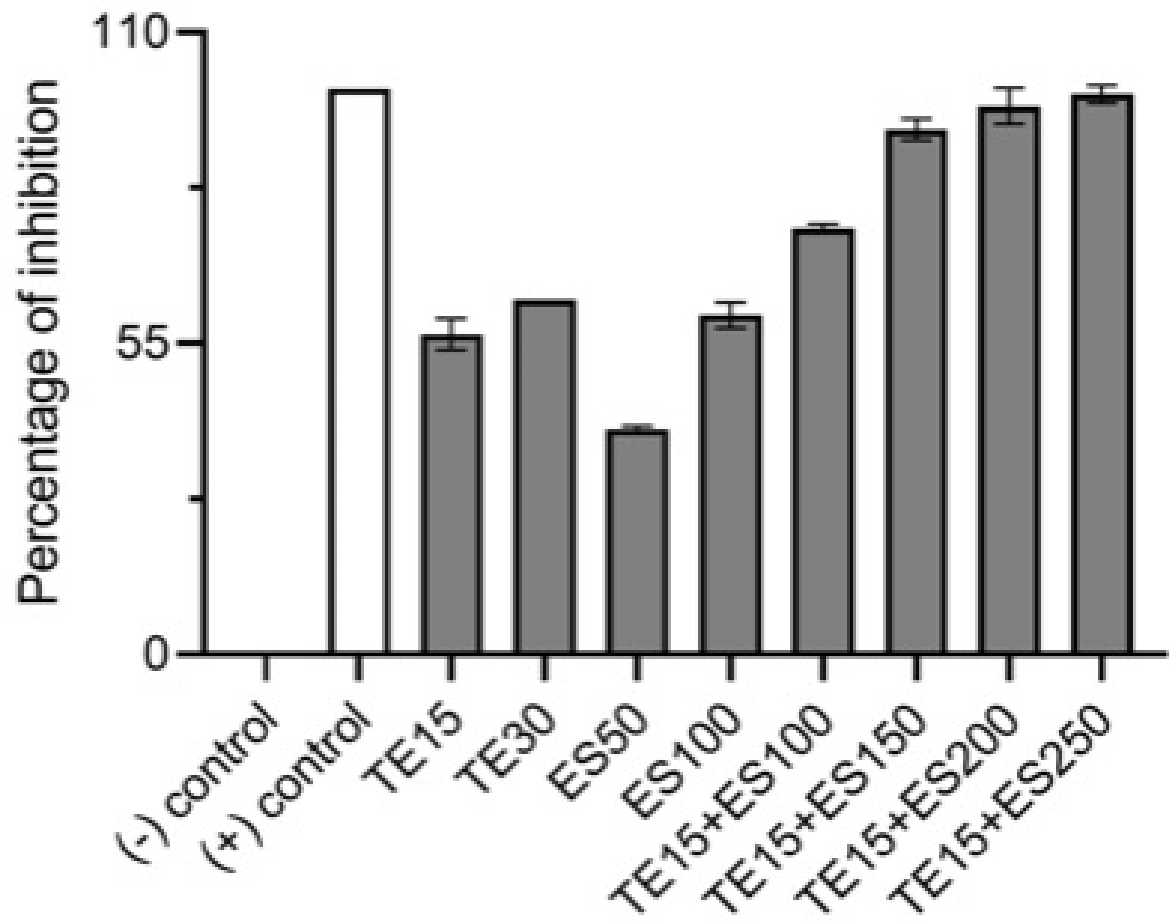

Figure 7. Effect of single and combinatorial treatments of tetracycline (TE) and EGCG-S (ES) on biofilm formation in S. aureus. The percentage of inhibition for (A) crystal violet assay and (B) Resazurin assay were calculated from respective measurement. (-) control: PBS buffer; (+) control: 10\% bleach. Experiments were repeated in triplicates. Means are shown with SD. The percentage of inhibition with different concentrations of tetracycline and EGCG-S indicated that TE10+ES200 inhibits biofilm formation of $S$. aureus most effectively. 

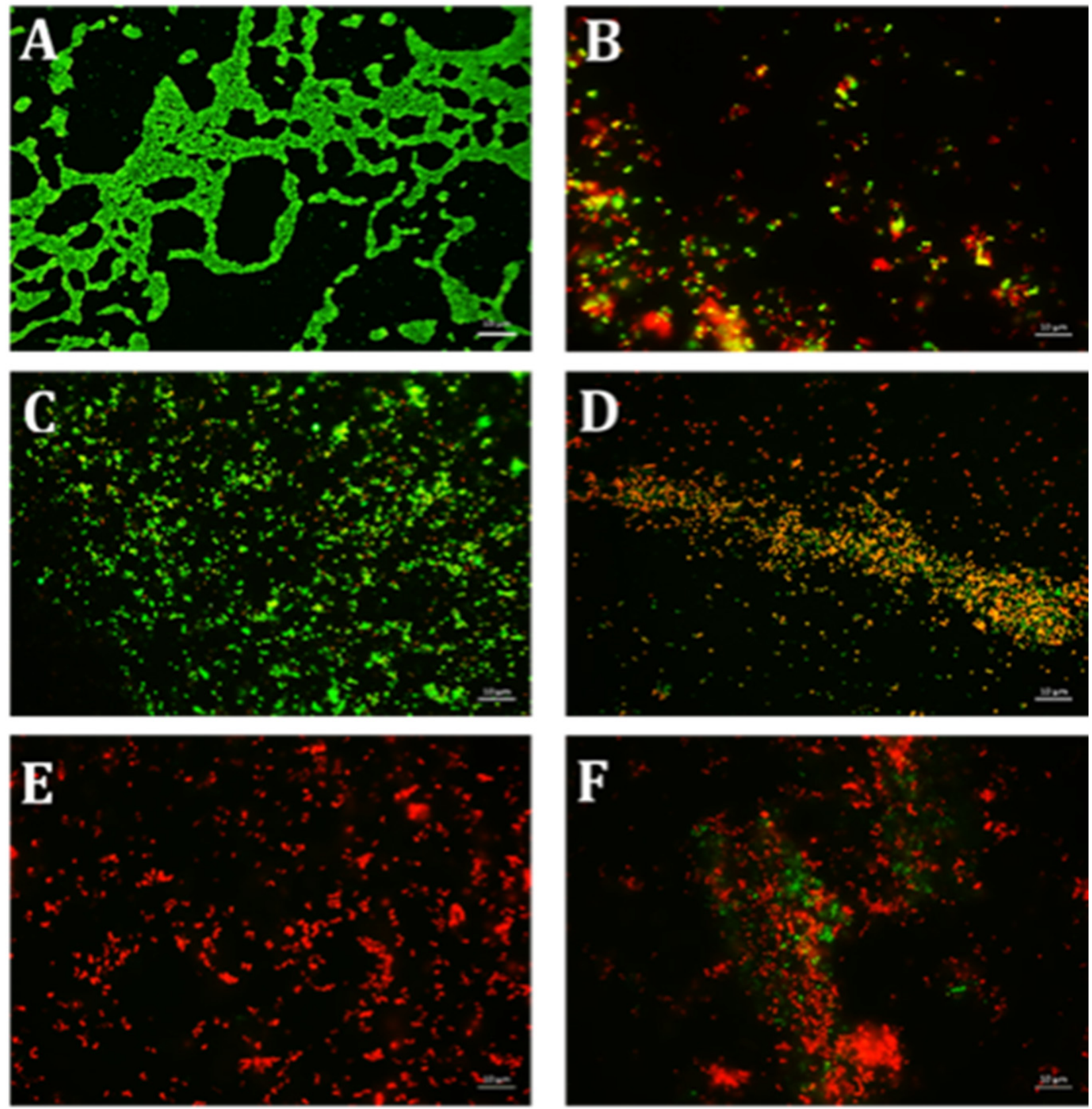

Figure 8. Fluorescence microscopic observation of cell viability on S. aureus biofilm formation. TE: tetracycline; ES: EGCG-S. Scale bar $=10 \mu \mathrm{m}$. (A) Control, (B) TE15, (C) ES100, (D) ES200, (E) TE15+ES200, and (F) TE15+ES250. The results indicated that TE15+ES200 severely affected the viability of the cells. 


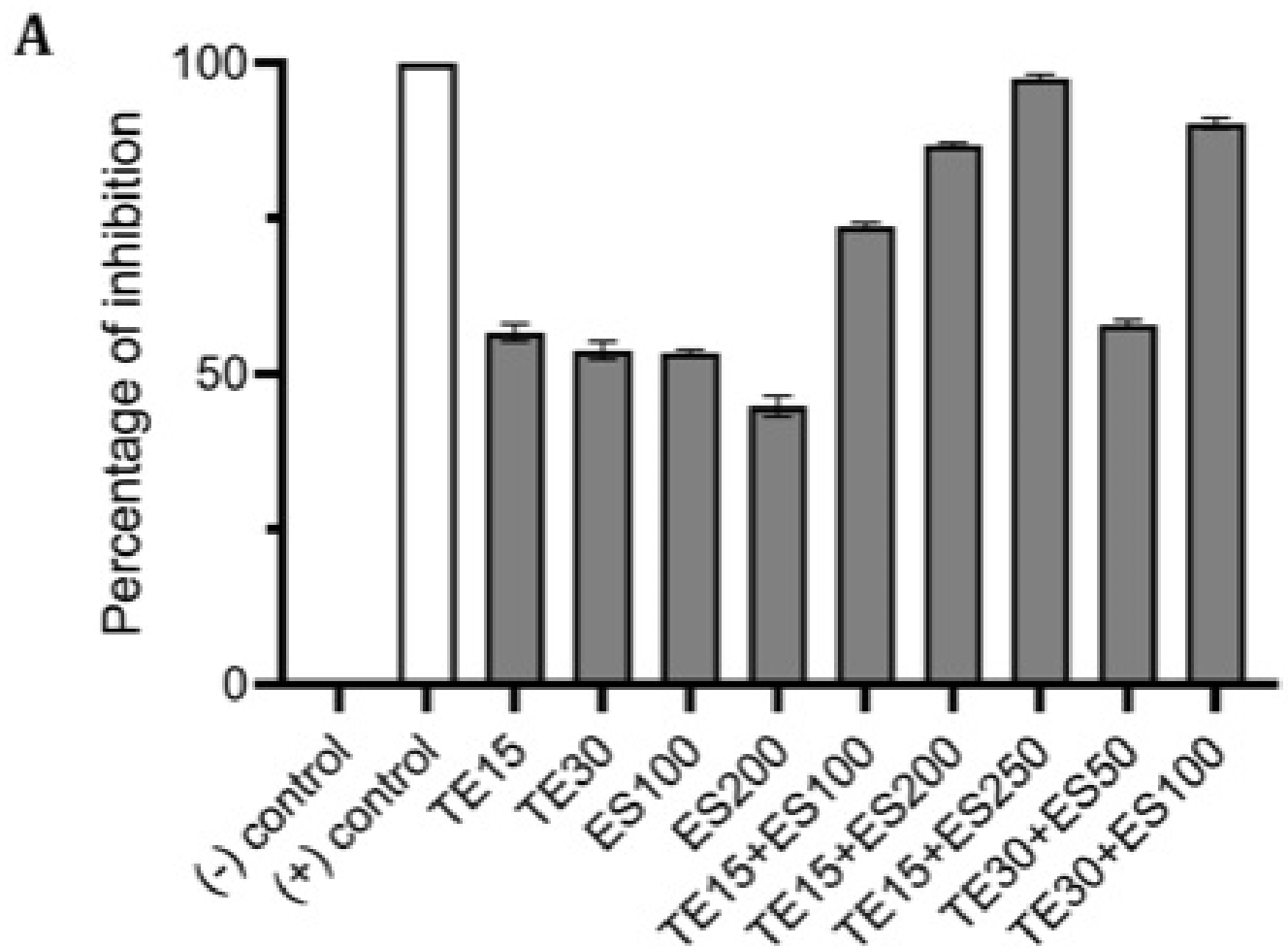

B

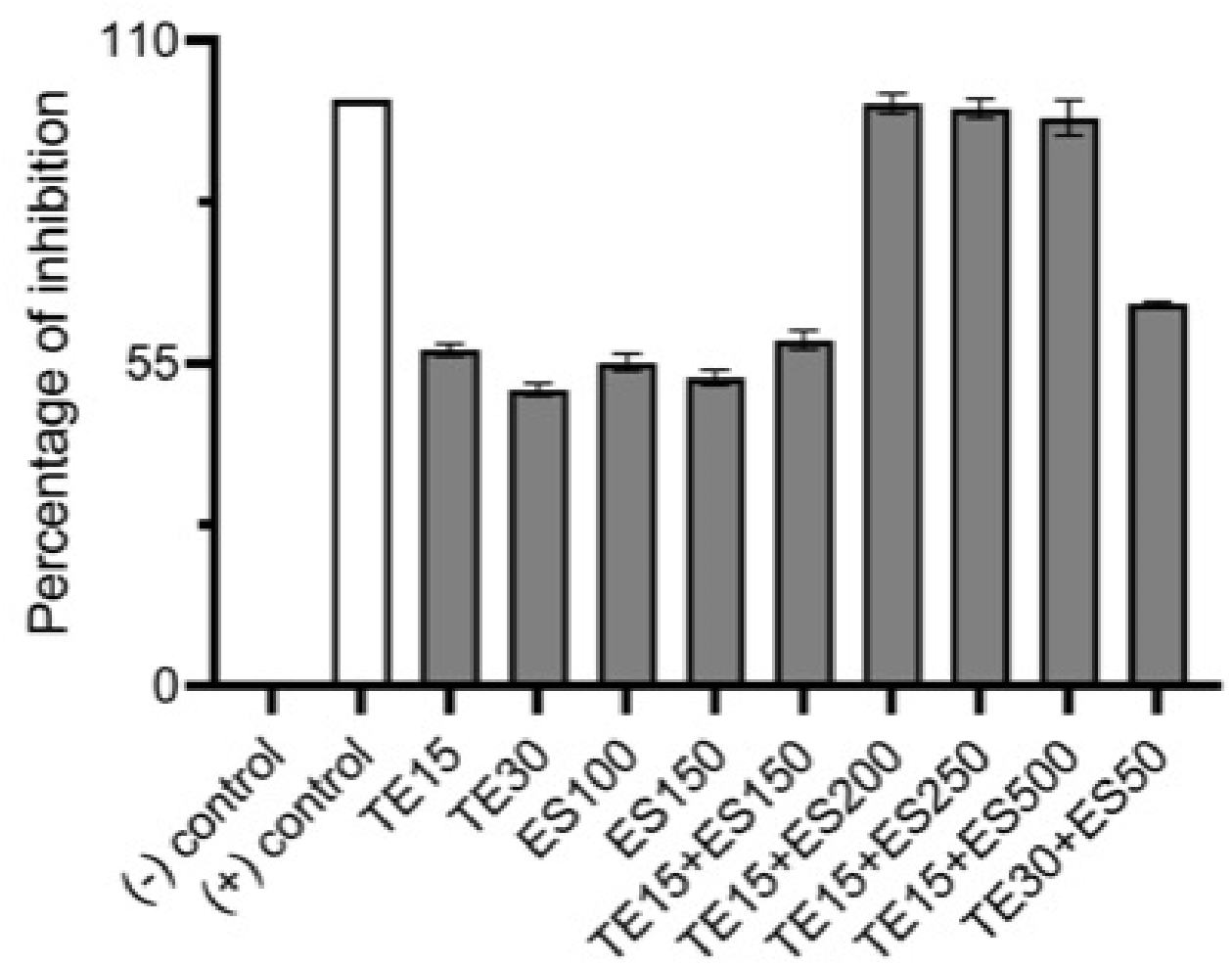

Figure 9. Effect of single and combined treatments of tetracycline (TE) and EGCG-S (ES) on S. epidermidis biofilm formation. The percentage of inhibition for (A) crystal violet assay and (B) Resazurin assay were calculated from respective measurement. (-) control: PBS buffer; (+) control: 10\% bleach. Experiments were repeated in triplicates. Means are shown with SD. The percentage of inhibition with different concentrations of tetracycline and EGCG-S indicated that TE10+ES250 inhibits biofilm formation of S. epidermidis most effectively. 

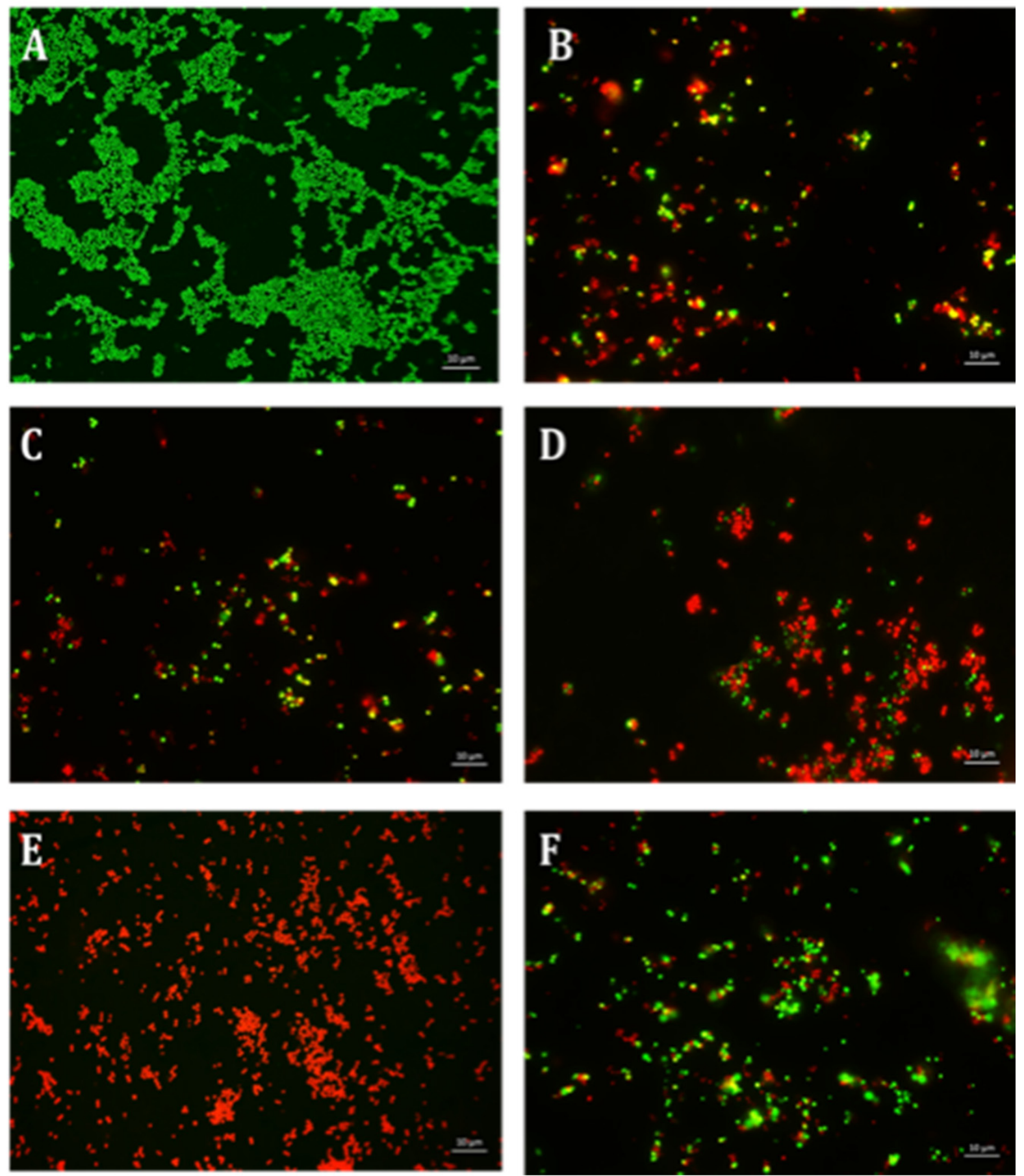

Figure 10. Fluorescence microscopic observation of cell viability on S. epidermidis biofilm formation. TE: tetracycline; ES: EGCG-S. Scale bar $=10 \mu \mathrm{m}$. (A) Control, (B) TE15, (C) ES100, (D) TE15+ES200, (E) TE15+ES250, and (F) TE30+ES100. The results indicated that TE15+ES250 severely affect the viability of the cells.

\section{Discussion}

EGCG exerts its antimicrobial effect on bacteria using various mechanisms, such as cell membrane damage, enzyme inhibition, impairment of fatty acid biosynthesis, and so forth [50]. EGCG has been shown to inhibit biofilm formation in diverse bacteria including E. coli [51], P. aeruginosa [23], Staphylococcal spp. [52], S. mutans [53], P. gingivalis [54], and Fusobacterium nucleatum [55] under in vitro and in vivo conditions. Recently, a detailed mechanism of action for EGCG was described using E. coli as a model system; EGCG synergistically targets amyloid curli fibers (anti-amyloidogenic) and cellulose synthesis, 
the two crucial processes of biofilm formation [56]. Furthermore, this study identified cell envelope stress as a second target for biofilm interference. Under stress, the cell downregulates the translation of trans-membrane proteins like protein complexes used in the biosynthesis of amyloid fibers and cellulose. This stress is potentially induced by the interaction of EGCG and the cell lipid bilayer [57], which can create temporal disturbances like perforations and grooves at the cell surface, thereby inducing cell damage [58-60]. EGCG impacts the integrity of the cell envelope, not only in E. coli but also in other bacteria, including $M$. smegmatis [61]. Although the trigger for this cell-envelope stress is unknown, it is proposed that reactive oxygen species (ROS) are involved in the bactericidal action of catechins [62]. ROS-mediated permanent damage has also been observed in a combination study of EGCG with antibiotic cefotaxime on E. coli cells [58]. In Staphylococcus spp. EGCG impairs the assembly of phenol-soluble modulins (PSMs) fibril formation and targets the preformed fibrils for disentanglement [63]. Another study found flavonoids can specifically prevent biofilm-associated proteins (Bap)-mediated biofilms [64]. Additionally, EGCG is shown to interfere with the polysaccharides that form the glycocalyx and bind peptidoglycan impairing the integrity of the cell wall, thereby suggesting that it can affect the initial attachment of biofilm to the surface [52]. EGCG has been found to be very effective in interfering with the action of amyloid fibers, FapC in P. aeruginosa [65] and amyloid proteins in S. mutans [66]. Besides, EGCG is involved in suppressing multiple virulence factors deployed by pathogenic bacteria to infections $[67,68]$. These studies suggest amyloid fibrils as a common target of EGCG, however EGCG can have multiple targets for a specific bacterial species and is efficient in interfering with multiple cellular processes without even entering a bacterial cell.

Some studies have suggested the synergism between EGCG and different antibiotics on inhibiting bacteria like methicillin-resistant S. aureus (MRSA), P. gingivalis, and K. pneumoniae $[22,69,70]$, and on bacterial biofilms. Biofilm formation by pathogenic organisms has developed tolerance to elevated levels of antimicrobials [71]. Most studies demonstrate that EGCG can work synergistically with antibiotics by breaking down the extracellular matrix components, thereby favoring antibiotics penetration and action on bacterial cells in biofilms [21-23], while other studies report opposite results [67,72]. These counterproductive effects raise questions about the efficacy of EGCG as its stability and bioavailability fluctuate with research conditions. EGCG, a hydrophilic molecule with low membrane permeability and chemical stability [73], is not a suitable candidate to be formulated in therapeutic preparations without rapid oxidation and loss of antimicrobial activity. Thus, in this study, we have used a patented (US8076484B2) esterified derivative of EGCG, EGCGStearate (EGCG-S) which improves the bioavailability significantly [74,75]. Previously, we reported that EGCG-S can be used as an anti-spore agent, as it inhibits germination of spores produced by Bacillus species [30]. In 2018, our study highlighted the anti-cariogenic property of EGCG-S as it was able to inhibit the growth and biofilm formation of $S$. mutans, an etiological agent of dental caries [31]. Taken together, evidence shows EGCG-S inhibits spore germination and biofilm formation. However, whether the synergism of EGCG-S with antibiotics extends to interfere with biofilm formation is still unknown. To the best of our knowledge, this research is the first to illustrate that the combination of EGCG-S and antibiotics not only inhibits bacterial growth, but also biofilm formation.

\section{Materials and Methods}

\subsection{Bacterial Cultures}

Five potential pathogenic biofilm producers, Escherichia coli (ATCC ${ }^{\circledR}$ CRM-8739), Pseudomonas aeruginosa (ATCC ${ }^{\circledR}$ CRM-9027), Staphylococcus aureus (ATCC ${ }^{\circledR}$ CRM-6538), Staphylococcus epidermidis (ATCC ${ }^{\circledR}$ 14990), and Mycobacterium smegmatis (ATCC ${ }^{\circledR}$ 19420) were grown aseptically on nutrient agar or broth. The stock cultures were stored at $4{ }^{\circ} \mathrm{C}$. Fresh overnight cultures were maintained at $37^{\circ} \mathrm{C}$ with constant shaking at $250 \mathrm{rpm}$. Gram staining was performed before each experiment to confirm the culture purity. 


\subsection{EGCG-S and Antibiotic Formulations}

EGCG-S (US Patent 8076484) purchased from Camellix LLC (Evans, GA, USA), was dissolved in absolute ethanol to make a stock concentration of $10 \mathrm{mg} / \mathrm{mL}$ prior to formulations. The stock was diluted to the required concentrations for each experiment. Phosphate buffer saline (PBS) was used as a negative control, while $10 \%$ bleach was used as a positive control. Antibiotics erythromycin (E0774) and tetracycline (T3258), were purchased from Sigma Aldrich (St. Louis, MO, USA). The stock concentration $(1000 \mu \mathrm{g} / \mathrm{mL})$ was prepared by dissolving antibiotics in absolute ethanol. Final concentrations of ethanol in the working solutions were all less than $5 \%$, which did not inhibit the growth of the bacteria. The solutions were filter sterilized and stored at $-20{ }^{\circ} \mathrm{C}$. The required concentrations were diluted from the stock aseptically prior to the experiment. The formulations consisted of varying concentrations of EGCG-S and antibiotics depending on the selected bacterium.

\subsection{Quantitative Absorbance-Based Biofilm Measurement (Crystal Violet Assay)}

The cultures were treated with EGCG-S and antibiotics alone and different formulations followed up by incubation at $37^{\circ} \mathrm{C}$ for 4 days. The liquid was aspirated, the biofilm (if any) was washed and then stained with $0.1 \%$ crystal violet (CV) for $24 \mathrm{~h}$. After strain aspiration and a final $1 \times$ PBS wash, the biofilms were dried for $24 \mathrm{~h}$. Biofilm was resuspended in 30\% acetic acid and the optical density (OD) were recorded at $595 \mathrm{~nm}$ [76]. All experiments were performed in triplicate, with mean and standard deviation calculated. These readings were then used to determine the percentage of biofilm inhibition. $10 \%$ bleach and PBS were used as the positive and negative control, respectively.

$$
\text { Percentage of Inhibition }=\left[\left(\mathrm{OD}_{\text {Untreated }}-\mathrm{OD}_{\text {Treated }}\right) / \mathrm{OD}_{\text {Untreated }}\right] \times 100
$$

\subsection{Quantitative Fluorescence-Based Biofilm Measurement (Resazurin Assay)}

Fresh log-phase bacterial cultures were incubated at $37^{\circ} \mathrm{C}$ for 4 days in 96 -well plates. After the media was aspirated, the biofilm was rinsed with $1 \times \mathrm{PBS}$ and stained with a $200 \mu \mathrm{M}$ Resazurin solution. After overnight incubation in the dark at $4{ }^{\circ} \mathrm{C}$, fluorescence was measured at excitation and an emission wavelength of $560 \mathrm{~nm}$ and $590 \mathrm{~nm}$ respectively using a microplate reader (Infinite 200 PRO, Tecan, Männedorf, Switzerland) adjusted to the fluorescent mode [47]. The Relative Light Units (RLU) were measured, and the percentage (\%) of inhibition was calculated for each treatment according to the following formula.

$$
\text { Percentage of Inhibition }=\left[\left(R_{L} U_{\text {Untreated }}-R U_{\text {Treated }}\right) / R L U_{\text {Untreated }}\right] \times 100
$$

\subsection{Quantitative Growth-Based Cell Viability Measurement (Colony Forming Unit Assay)}

Bacterial cultures were incubated at $37^{\circ} \mathrm{C}$ for 4 days in 24 -well plates. The biofilm attached to the well plate was scrapped and suspended in $100 \mu \mathrm{L}$ of deionized water. The samples were serially diluted (from $10^{0}$ to $10^{-4}$ ) and $100 \mu \mathrm{L}$ of each dilution was spread plated on nutrient agar aseptically. The media plates were incubated overnight at $37^{\circ} \mathrm{C}$. Colony-forming units (CFUs) were recorded and percentage of inhibition was calculated using the following formula. $\mathrm{LD}_{50}$ represents the lethal concentration to $50 \%$ of the population.

$$
\text { Percentage of Inhibition }=\left[\left(\mathrm{CFU}_{\text {Untreated }}-\mathrm{CFU}_{\text {Treated }}\right) / \mathrm{CFU}_{\text {Untreated }}\right] \times 100
$$

Additionally, the CFU measurement was used to calculate log10 (fold) reduction using the following equation:

$$
\log \text { Reduction }=\log _{10}\left(\mathrm{CFU}_{\text {Control }} / \mathrm{CFU}_{\text {Treated }}\right)
$$

\subsection{Qualitative Microscopy-Based Cell Viability Assay}

The LIVE/DEAD ${ }^{\circledR}$ BacLight $^{\mathrm{TM}}$ Bacterial Viability Kit (Thermo Fisher, Waltham, MA, USA) was used according to the manufacture manual. The scrapped biofilms were grown 
in a 6-well plate with/without different treatments. After incubation at $37^{\circ} \mathrm{C}$ for 4 days, the liquid was aspirated exposing the biofilms adhering to the well surface. The biofilms were then washed and stained with dye mixture. After proper staining coverslips were placed in the well to view under the microscope. The molecular probes used were SYTO 9, a greenfluorescent membrane-permeant dye that stains live cell, and propidium iodide (PI), red fluorescence dye that stains dead cells due to damaged cell membrane. All samples were viewed under a fluorescent microscope (Axio Scope A1, Carl Zeiss, München, Germany).

\subsection{Statistical Analysis}

All assays were performed in triplicate. Statistically significant differences between control and test were analyzed by one-way analysis of variance (one-way ANOVA) with Dunnett's multiple comparison post-test at $p<0.05$. The analyses were carried out in GraphPad Prism Software (GraphPad Software Inc., San Diego, CA, USA).

\section{Conclusions}

This study successfully demonstrated the synergistic inhibitory effects of a modified green tea polyphenol, EGCG-S, in combination with antibiotics on biofilm formation in five distinct potential pathogenic bacteria. Inhibition of biofilm formation was determined after an initial assessment of the inhibitory nature of EGCG-S and antibiotics on the growth of the cells. The $\mathrm{LD}_{50}$ of erythromycin for all Gram-negative bacteria (E. coli, M. smegmatis, and P. aeruginosa) is $15 \mu \mathrm{g} / \mathrm{mL}$. The LD Lo $_{0}$ of EGCG-S is $50 \mu \mathrm{g} / \mathrm{mL}$ for E. coli and P. aeruginosa: $100 \mu \mathrm{g} / \mathrm{mL}$ for M. smegmatis. As for both Gram-positive bacteria (S. aureus and S. epidermidis), $\mathrm{LD}_{50}$ is $15 \mu \mathrm{g} / \mathrm{mL}$ for tetracycline and $50 \mu \mathrm{g} / \mathrm{mL}$ for EGCG-S. The optimal formulation of EGCG-S and antibiotics specific for every bacterium tested was determined by the combinatorial analysis of quantitative measurements from three different assays ( $\mathrm{CFU}, \mathrm{CV}$, and resazurin). The colony-forming unit (CFU) assay provided preliminary information on the concentrations, of EGCG-S and antibiotics, necessary for their effects on biofilm formation. Although CFU data, indicating log-reduction of about 1.0, is not enough to strongly support synergism, it does reflect similar trends in comparison with the crystal violet (CV) and Resazurin assay. These experiments confirmed that EGCG-S in combination with antibiotics was able to maximally reduce biofilm formation in pathogenic bacteria. The findings were further confirmed by qualitative cell viability analysis and the optimal formulation for each bacterium was determined.

Author Contributions: Conceptualization, methodology, resources, data curation, writing-review and editing, project administration, and funding acquisition, L.H.L. and T.C.; formal analysis, and writing-original draft preparation, S.S.; investigation, S.S., L.H.L., and T.C. All authors have read and agreed to the published version of the manuscript.

Funding: This work was supported by Montclair State University (MSU) Faculty Scholarship Program (FSP) to L.H.L.; MSU Graduate Teaching Assistantship and Wehner Research Scholarship to S.S.; Seton Hall University (SHU) Research Fund and William and Doreen Wong Foundation to T.C.

Data Availability Statement: Data is contained within the article.

Conflicts of Interest: The authors declare no conflict of interest.

\section{References}

1. Costerton, J.W.; Stewart, P.S.; Greenberg, E.P. Bacterial biofilms: A common cause of persistent infections. Science 1999, $284,1318-1322$. [CrossRef] [PubMed]

2. Stewart, P.S.; Costerton, J.W. Antibiotic resistance of bacteria in biofilms. Lancet 2001, 358, 135-138. [CrossRef]

3. Romling, U.; Kjelleberg, S.; Normark, S.; Nyman, L.; Uhlin, B.E.; Akerlund, B. Microbial biofilm formation: A need to act. J. Intern. Med. 2014, 276, 98-110. [CrossRef]

4. Jamal, M.; Ahmad, W.; Andleeb, S.; Jalil, F.; Imran, M.; Nawaz, M.A.; Hussain, T.; Ali, M.; Rafiq, M.; Kamil, M.A. Bacterial biofilm and associated infections. J. Chin. Med. Assoc. 2018, 81, 7-11. [CrossRef] [PubMed]

5. Siddiqui, A.R.; Bernstein, J.M. Chronic wound infection: Facts and controversies. Clin. Dermatol. 2010, 28, 519-526. [CrossRef]

6. Donlan, R.M. Biofilms and device-associated infections. Emerg. Infect. Dis. 2001, 7, 277-281. [CrossRef] 
7. O'Gara, J.P.; Humphreys, H. Staphylococcus epidermidis biofilms: Importance and implications. J. Med. Microbiol. $2001,50,582-587$. [CrossRef]

8. Ojha, A.; Anand, M.; Bhatt, A.; Kremer, L.; Jacobs, W.R., Jr.; Hatfull, G.F. GroEL1: A dedicated chaperone involved in mycolic acid biosynthesis during biofilm formation in mycobacteria. Cell 2005, 123, 861-873. [CrossRef]

9. Yang, C.S.; Chen, G.; Wu, Q. Recent scientific studies of a traditional Chinese medicine, tea, on prevention of chronic diseases. J. Tradit. Complement. Med. 2014, 4, 17-23. [CrossRef]

10. Forester, S.C.; Lambert, J.D. The role of antioxidant versus pro-oxidant effects of green tea polyphenols in cancer prevention. Mol. Nutr. Food Res. 2011, 55, 844-854. [CrossRef]

11. Koutelidakis, A.E.; Andritsos, N.D.; Kabolis, D.; Kapsokefalou, M.; Drosinos, E.H. Antioxidant and antimicrobial properties of tea and aromatic plant extracts against bacterial foodborne pathogens: A comparative evaluation. Curr. Top. Nutraceutical Res. 2016, 14, 133-141.

12. Min, K.J.; Kwon, T.K. Anticancer effects and molecular mechanisms of epigallocatechin-3-gallate. Integr. Med. Res. 2014, 3, 16-24. [CrossRef] [PubMed]

13. Ohishi, T.; Goto, S.; Monira, P.; Isemura, M.; Nakamura, Y. Anti-inflammatory Action of Green Tea. Anti-Inflamm. Anti-Allergy Agents Med. Chem. 2016, 15, 74-90. [CrossRef] [PubMed]

14. Isaacs, C.E.; Wen, G.Y.; Xu, W.; Jia, J.H.; Rohan, L.; Corbo, C.; Di Maggio, V.; Jenkins, E.C., Jr.; Hillier, S. Epigallocatechin gallate inactivates clinical isolates of herpes simplex virus. Antimicrob. Agents Chemother. 2008, 52, 962-970. [CrossRef]

15. Paterson, I.; Anderson, E.A. The renaissance of natural products as drug candidates. Science 2005, 310, 451-453. [CrossRef]

16. Reygaert, W.C. Green Tea Catechins: Their Use in Treating and Preventing Infectious Diseases. BioMed Res. Int. 2018, $2018,9105261$. [CrossRef]

17. Steinmann, J.; Buer, J.; Pietschmann, T.; Steinmann, E. Anti-infective properties of epigallocatechin-3-gallate (EGCG), a component of green tea. Br. J. Pharmacol. 2013, 168, 1059-1073. [CrossRef]

18. Hengge, R. Targeting Bacterial Biofilms by the Green Tea Polyphenol EGCG. Molecules 2019, 24, 2403. [CrossRef]

19. Haghjoo, B.; Lee, L.H.; Habiba, U.; Tahir, H.; Olabi, M.; Chu, T. The synergistic effects of green tea polyphenols and antibiotics against potential pathogens. Adv. Biosci. Biotechnol. 2013, 4, 959-967. [CrossRef]

20. Stapleton, P.D.; Taylor, P.W. Methicillin resistance in Staphylococcus aureus: Mechanisms and modulation. Sci. Prog. 2002, 85, 57-72. [CrossRef]

21. Sudano Roccaro, A.; Blanco, A.R.; Giuliano, F.; Rusciano, D.; Enea, V. Epigallocatechin-gallate enhances the activity of tetracycline in staphylococci by inhibiting its efflux from bacterial cells. Antimicrob. Agents Chemother. 2004, 48, 1968-1973. [CrossRef] [PubMed]

22. Fournier-Larente, J.; Morin, M.P.; Grenier, D. Green tea catechins potentiate the effect of antibiotics and modulate adherence and gene expression in Porphyromonas gingivalis. Arch. Oral Biol. 2016, 65, 35-43. [CrossRef] [PubMed]

23. Stenvang, M.; Dueholm, M.S.; Vad, B.S.; Seviour, T.; Zeng, G.; Geifman-Shochat, S.; Sondergaard, M.T.; Christiansen, G.; Meyer, R.L.; Kjelleberg, S.; et al. Epigallocatechin Gallate Remodels Overexpressed Functional Amyloids in Pseudomonas aeruginosa and Increases Biofilm Susceptibility to Antibiotic Treatment. J. Biol. Chem. 2016, 291, 26540-26553. [CrossRef] [PubMed]

24. Hong, J.; Lu, H.; Meng, X.; Ryu, J.H.; Hara, Y.; Yang, C.S. Stability, cellular uptake, biotransformation, and efflux of tea polyphenol (-)-epigallocatechin-3-gallate in HT-29 human colon adenocarcinoma cells. Cancer Res. 2002, 62, 7241-7246.

25. Mereles, D.; Hunstein, W. Epigallocatechin-3-gallate (EGCG) for clinical trials: More pitfalls than promises? Int. J. Mol. Sci. 2011, 12, 5592-5603. [CrossRef]

26. Widyaningrum, N.; Fudholi, A.; Sudarsono, P.; Setyowati, E.P. Stability of epigallocatechin gallate (EGCG) from green tea (Camellia sinensis) and its antibacterial activity against Staphylococcus epidermidis ATCC 35984 and Propionibacterium acnes ATCC 6919. Asian J. Biol. Sci. 2015, 8, 93-101. [CrossRef]

27. Yang, H.; Landis-Piwowar, K.; Chan, T.H.; Dou, Q.P. Green tea polyphenols as proteasome inhibitors: Implication in chemoprevention. Curr. Cancer Drug Targets 2011, 11, 296-306. [CrossRef]

28. Chu, T.; Lee, L.H.; Aponte, T.; Lopez, S.; Lalata, G.; Herrera, G.; Yussof, A.; Dickinson, D.; Hsu, S. Sporicidal activity of novel formulations containing lipophilic epigallocatechin-3-gallate and natural ingredients. Microbiol. Infect. Dis. 2019, 3, 1-6. [CrossRef]

29. Chu, T.; Lee, L.H.; Yussof, A.; Lopez, S.; Herrera, G.; Luna, P.; Uddin, M.; Wu, L.; Murzaku, J.; Dickinson, D.; et al. Enhanced sporicidal activity of alcohol and epigallocatechin-palmitate-based hand hygiene formulations comprised of plant-derived compounds. J. Biosci. Med. 2020, 8, 89-99. [CrossRef]

30. Ali, B.; Lee, L.H.; Laskar, N.; Shaikh, N.; Tahir, H.; Hsu, S.; Newby, R.; Valsechi-Diaz, J.; Chu, T. Modified green tea polyphenols, EGCG-S and LTP, inhibit endospore in three Bacillus spp. Adv. Microbiol. 2017, 7, 175-187. [CrossRef]

31. Melok, A.L.; Lee, L.H.; Mohamed Yussof, S.A.; Chu, T. Green Tea Polyphenol Epigallocatechin-3-Gallate-Stearate Inhibits the Growth of Streptococcus mutans: A Promising New Approach in Caries Prevention. Dent. J. 2018, 6, 38. [CrossRef] [PubMed]

32. Yussof, A.; Habiba, U.; Liaw, D.; Chu, T.; Lee, L.H. Epigallocatechin gallate-stearate enhances the efficacy of antibiotics. Open J. Med. Microbiol. 2019, 9, 77-94. [CrossRef]

33. Karigoudar, R.M.; Karigoudar, M.H.; Wavare, S.M.; Mangalgi, S.S. Detection of biofilm among uropathogenic Escherichia coli and its correlation with antibiotic resistance pattern. J. Lab. Physicians 2019, 11, 17-22. [CrossRef] [PubMed] 
34. Donlan, R.M.; Costerton, J.W. Biofilms: Survival mechanisms of clinically relevant microorganisms. Clin. Microbiol. Rev. 2002, 15, 167-193. [CrossRef] [PubMed]

35. Suman, E.; Jose, J.; Varghese, S.; Kotian, M.S. Study of biofilm production in Escherichia coli causing urinary tract infection. Indian J. Med. Microbiol. 2007, 25, 305-306. [CrossRef]

36. Bhunu, B.; Mautsa, R.; Mukanganyama, S. Inhibition of biofilm formation in Mycobacterium smegmatis by Parinari curatellifolia leaf extracts. BMC Complement. Altern. Med. 2017, 17, 285. [CrossRef]

37. Kaur, P.; Ghosh, A.; Krishnamurthy, R.V.; Bhattacharjee, D.G.; Achar, V.; Datta, S.; Narayanan, S.; Anbarasu, A.; Ramaiah, S. A high-throughput cidality screen for Mycobacterium tuberculosis. PLoS ONE 2015, 10, e0117577. [CrossRef]

38. Esteban, J.; Garcia-Coca, M. Mycobacterium Biofilms. Front. Microbiol. 2017, 8, 2651. [CrossRef]

39. Costerton, W.; Veeh, R.; Shirtliff, M.; Pasmore, M.; Post, C.; Ehrlich, G. The application of biofilm science to the study and control of chronic bacterial infections. J. Clin. Investig. 2003, 112, 1466-1477. [CrossRef]

40. Kiedrowski, M.R.; Gaston, J.R.; Kocak, B.R.; Coburn, S.L.; Lee, S.; Pilewski, J.M.; Myerburg, M.M.; Bomberger, J.M. Staphylococcus aureus Biofilm Growth on Cystic Fibrosis Airway Epithelial Cells Is Enhanced during Respiratory Syncytial Virus Coinfection. mSphere 2018, 3. [CrossRef]

41. Costerton, J.W.; Lewandowski, Z.; Caldwell, D.E.; Korber, D.R.; Lappin-Scott, H.M. Microbial biofilms. Annu. Rev. Microbiol. 1995, 49, 711-745. [CrossRef] [PubMed]

42. Fey, P.D.; Olson, M.E. Current concepts in biofilm formation of Staphylococcus epidermidis. Future Microbiol. $2010,5,917-933$. [CrossRef] [PubMed]

43. Wilson, C.; Lukowicz, R.; Merchant, S.; Valquier-Flynn, H.; Caballero, J.; Sandoval, J.; Okuom, M.; Huber, C.; Brooks, T.D.; Wilson, E.; et al. Quantitative and Qualitative Assessment Methods for Biofilm Growth: A Mini-review. Res. Rev. J. Eng. Technol. 2017, 6. Available online: https:/ / www.ncbi.nlm.nih.gov/pmc/articles/PMC6133255/ (accessed on 19 January 2021).

44. Sandberg, M.E.; Schellmann, D.; Brunhofer, G.; Erker, T.; Busygin, I.; Leino, R.; Vuorela, P.M.; Fallarero, A. Pros and cons of using resazurin staining for quantification of viable Staphylococcus aureus biofilms in a screening assay. J. Microbiol. Methods 2009, 78, 104-106. [CrossRef] [PubMed]

45. Peeters, E.; Nelis, H.J.; Coenye, T. Comparison of multiple methods for quantification of microbial biofilms grown in microtiter plates. J. Microbiol. Methods 2008, 72, 157-165. [CrossRef] [PubMed]

46. Brackman, G.; Hillaert, U.; Van Calenbergh, S.; Nelis, H.J.; Coenye, T. Use of quorum sensing inhibitors to interfere with biofilm formation and development in Burkholderia multivorans and Burkholderia cenocepacia. Res. Microbiol. 2009, 160, 144-151. [CrossRef]

47. Mariscal, A.; Lopez-Gigosos, R.M.; Carnero-Varo, M.; Fernandez-Crehuet, J. Fluorescent assay based on resazurin for detection of activity of disinfectants against bacterial biofilm. Appl. Microbiol. Biotechnol. 2009, 82, 773-783. [CrossRef]

48. Peeters, E.; Nelis, H.J.; Coenye, T. Evaluation of the efficacy of disinfection procedures against Burkholderia cenocepacia biofilms. J. Hosp. Infect. 2008, 70, 361-368. [CrossRef]

49. CLSI. Performance Standards for Antimicrobial Disk Susceptibility Tests, 12th ed.; Approved Standard; Clinical and Laboratory Standards Institute: Wayne, PA, USA, 2018.

50. Reygaert, W.C. The antimicrobial possibilities of green tea. Front. Microbiol. 2014, 5, 434. [CrossRef]

51. Arita-Morioka, K.I.; Yamanaka, K.; Mizunoe, Y.; Tanaka, Y.; Ogura, T.; Sugimoto, S. Inhibitory effects of Myricetin derivatives on curli-dependent biofilm formation in Escherichia coli. Sci. Rep. 2018, 8, 8452. [CrossRef]

52. Blanco, A.R.; Sudano-Roccaro, A.; Spoto, G.C.; Nostro, A.; Rusciano, D. Epigallocatechin gallate inhibits biofilm formation by ocular staphylococcal isolates. Antimicrob. Agents Chemother. 2005, 49, 4339-4343. [CrossRef] [PubMed]

53. Xu, X.; Zhou, X.D.; Wu, C.D. The tea catechin epigallocatechin gallate suppresses cariogenic virulence factors of Streptococcus mutans. Antimicrob. Agents Chemother. 2011, 55, 1229-1236. [CrossRef] [PubMed]

54. Asahi, Y.; Noiri, Y.; Miura, J.; Maezono, H.; Yamaguchi, M.; Yamamoto, R.; Azakami, H.; Hayashi, M.; Ebisu, S. Effects of the tea catechin epigallocatechin gallate on Porphyromonas gingivalis biofilms. J. Appl. Microbiol. 2014, 116, 1164-1171. [CrossRef] [PubMed]

55. Ben Lagha, A.; Haas, B.; Grenier, D. Tea polyphenols inhibit the growth and virulence properties of Fusobacterium nucleatum. Sci. Rep. 2017, 7, 44815. [CrossRef]

56. Serra, D.O.; Mika, F.; Richter, A.M.; Hengge, R. The green tea polyphenol EGCG inhibits E. coli biofilm formation by impairing amyloid curli fibre assembly and downregulating the biofilm regulator CsgD via the sigma(E)-dependent sRNA RybB. Mol. Microbiol. 2016, 101, 136-151. [CrossRef]

57. Kajiya, K.; Kumazawa, S.; Naito, A.; Nakayama, T. Solid-state NMR analysis of the orientation and dynamics of epigallocatechin gallate, a green tea polyphenol, incorporated into lipid bilayers. Magn. Reson. Chem. 2008, 46, 174-177. [CrossRef]

58. Cui, Y.; Kim, S.H.; Kim, H.; Yeom, J.; Ko, K.; Park, W.; Park, S. AFM probing the mechanism of synergistic effects of the green tea polyphenol (-)-epigallocatechin-3-gallate (EGCG) with cefotaxime against extended-spectrum beta-lactamase (ESBL)-producing Escherichia coli. PLoS ONE 2012, 7, e48880. [CrossRef]

59. Hoshino, N.; Kimura, T.; Yamaji, A.; Ando, T. Damage to the cytoplasmic membrane of Escherichia coli by catechin-copper (II) complexes. Free Radic. Biol. Med. 1999, 27, 1245-1250. [CrossRef]

60. Ikigai, H.; Nakae, T.; Hara, Y.; Shimamura, T. Bactericidal catechins damage the lipid bilayer. Biochim. Biophys. Acta 1993, 1147, 132-136. [CrossRef] 
61. Sun, T.; Qin, B.; Gao, M.; Yin, Y.; Wang, C.; Zang, S.; Li, X.; Zhang, C.; Xin, Y.; Jiang, T. Effects of epigallocatechin gallate on the cell-wall structure of Mycobacterial smegmatis mc $^{2} 155$. Nat. Prod. Res. 2015, 29, 2122-2124. [CrossRef]

62. Arakawa, H.; Maeda, M.; Okubo, S.; Shimamura, T. Role of hydrogen peroxide in bactericidal action of catechin. Biol. Pharm. Bull. 2004, 27, 277-281. [CrossRef] [PubMed]

63. Marinelli, P.; Pallares, I.; Navarro, S.; Ventura, S. Dissecting the contribution of Staphylococcus aureus alpha-phenol-soluble modulins to biofilm amyloid structure. Sci. Rep. 2016, 6, 34552. [CrossRef] [PubMed]

64. Matilla-Cuenca, L.; Gil, C.; Cuesta, S.; Rapun-Araiz, B.; Ziemyte, M.; Mira, A.; Lasa, I.; Valle, J. Antibiofilm activity of flavonoids on staphylococcal biofilms through targeting BAP amyloids. Sci. Rep. 2020, 10, 18968. [CrossRef] [PubMed]

65. Najarzadeh, Z.; Mohammad-Beigi, H.; Nedergaard Pedersen, J.; Christiansen, G.; Sonderby, T.V.; Shojaosadati, S.A.; Morshedi, D.; Stromgaard, K.; Meisl, G.; Sutherland, D.; et al. Plant Polyphenols Inhibit Functional Amyloid and Biofilm Formation in Pseudomonas Strains by Directing Monomers to Off-Pathway Oligomers. Biomolecules 2019, 9, 659. [CrossRef] [PubMed]

66. Besingi, R.N.; Wenderska, I.B.; Senadheera, D.B.; Cvitkovitch, D.G.; Long, J.R.; Wen, Z.T.; Brady, L.J. Functional amyloids in Streptococcus mutans, their use as targets of biofilm inhibition and initial characterization of SMU_63c. Microbiology 2017, 163, 488-501. [CrossRef]

67. Bikels-Goshen, T.; Landau, E.; Saguy, S.; Shapira, R. Staphylococcal strains adapted to epigallocathechin gallate (EGCG) show reduced susceptibility to vancomycin, oxacillin and ampicillin, increased heat tolerance, and altered cell morphology. Int. J. Food Microbiol. 2010, 138, 26-31. [CrossRef] [PubMed]

68. Song, M.; Teng, Z.; Li, M.; Niu, X.; Wang, J.; Deng, X. Epigallocatechin gallate inhibits Streptococcus pneumoniae virulence by simultaneously targeting pneumolysin and sortase A. J. Cell. Mol. Med. 2017, 21, 2586-2598. [CrossRef]

69. Dey, D.; Ghosh, S.; Ray, R.; Hazra, B. Polyphenolic Secondary Metabolites Synergize the Activity of Commercial Antibiotics against Clinical Isolates of beta-Lactamase-producing Klebsiella pneumoniae. Phytother. Res. 2016, 30, 272-282. [CrossRef]

70. Hu, Z.Q.; Zhao, W.H.; Asano, N.; Yoda, Y.; Hara, Y.; Shimamura, T. Epigallocatechin gallate synergistically enhances the activity of carbapenems against methicillin-resistant Staphylococcus aureus. Antimicrob. Agents Chemother. 2002, 46, 558-560. [CrossRef]

71. Wu, H.; Moser, C.; Wang, H.Z.; Hoiby, N.; Song, Z.J. Strategies for combating bacterial biofilm infections. Int. J. Oral Sci. 2015, 7, 1-7. [CrossRef]

72. O’May, C.; Ciobanu, A.; Lam, H.; Tufenkji, N. Tannin derived materials can block swarming motility and enhance biofilm formation in Pseudomonas aeruginosa. Biofouling 2012, 28, 1063-1076. [CrossRef] [PubMed]

73. Mori, S.; Miyake, S.; Kobe, T.; Nakaya, T.; Fuller, S.D.; Kato, N.; Kaihatsu, K. Enhanced anti-influenza A virus activity of (-)epigallocatechin-3-O-gallate fatty acid monoester derivatives: Effect of alkyl chain length. Bioorg. Med. Chem. Lett. 2008, 18, 4249-4252. [CrossRef] [PubMed]

74. Chen, P.; Dickinson, D.; Hsu, S. Lipid-soluble green tea polyphenols: Stabilized for effective formulation. In Handbook of Green Tea and Health Research, 1st ed.; Mckinley, H., Jamieson, M., Eds.; Nova Science Publishers, Inc.: New York, NY, USA, 2009 ; pp. 45-62.

75. Chen, P.; Tan, Y.; Sun, D.; Zheng, X.M. A novel long-chain acyl-derivative of epigallocatechin-3-O-gallate prepared and purified from green tea polyphenols. J. Zhejiang Univ. Sci. 2003, 4, 714-718. [CrossRef] [PubMed]

76. Nowak, J.; Cruz, C.D.; Palmer, J.; Fletcher, G.C.; Flint, S. Biofilm formation of the L. monocytogenes strain $15 \mathrm{G} 01$ is influenced by changes in environmental conditions. J. Microbiol. Methods 2015, 119, 189-195. [CrossRef] [PubMed] 